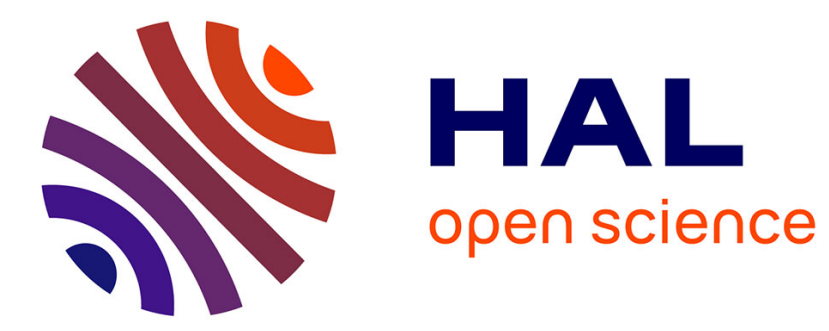

\title{
Crossing and zipping: molecular duties of the ZMM proteins in meiosis
}

\author{
Alexandra Pyatnitskaya, Valérie Borde, Arnaud de Muyt
}

\section{To cite this version:}

Alexandra Pyatnitskaya, Valérie Borde, Arnaud de Muyt. Crossing and zipping: molecular duties of the ZMM proteins in meiosis. Chromosoma, 2019, 10.1007/s00412-019-00714-8 . hal-02413016

\section{HAL Id: hal-02413016 https://hal.science/hal-02413016}

Submitted on 16 Dec 2019

HAL is a multi-disciplinary open access archive for the deposit and dissemination of scientific research documents, whether they are published or not. The documents may come from teaching and research institutions in France or abroad, or from public or private research centers.
L'archive ouverte pluridisciplinaire HAL, est destinée au dépôt et à la diffusion de documents scientifiques de niveau recherche, publiés ou non, émanant des établissements d'enseignement et de recherche français ou étrangers, des laboratoires publics ou privés. 


\title{
Crossing and zipping: molecular duties of the ZMM proteins in meiosis
}

\author{
Alexandra Pyatnitskaya1,2, Valérie Borde ${ }^{1,2, *}$ and Arnaud De Muyt1,2,* \\ ${ }^{1}$ Institut Curie, PSL Research University, CNRS, UMR3244, Paris, France. \\ ${ }^{2}$ Paris Sorbonne Université, Paris, France. \\ *Valérie Borde, valerie.borde@curie.fr; Arnaud De Muyt, arnaud.de-muyt@curie.fr
}

Keywords : meiosis, crossover, recombination, synaptonemal complex, ZMM 


\begin{abstract}
Accurate segregation of homologous chromosomes during meiosis depends on the ability of meiotic cells to promote reciprocal exchanges between parental DNA strands, known as crossovers (COs). For most organisms, including budding yeast and other fungi, mammals, nematodes and plants, the major CO pathway depends on ZMM proteins, a set of molecular actors specifically devoted to recognize and stabilize CO-specific DNA intermediates that are formed during homologous recombination. The progressive implementation of ZMM-dependent COs takes place within the context of the synaptonemal complex (SC), a proteinaceous structure that polymerizes between homologs and participates in close homolog juxtaposition during prophase I of meiosis. While SC polymerization starts from ZMM-bound sites and ZMM proteins are required for SC polymerization in budding yeast and the fungus Sordaria, other organisms differ in their requirement for ZMM in SC elongation. This review provides an overview of ZMM functions and discusses their collaborative tasks for CO formation and SC assembly, based on recent findings and on a comparison of different model organisms.
\end{abstract}




\section{Introduction}

During meiosis, chromosomes undergo a series of large-scale structural changes as well as localized genetic exchanges by homologous recombination that contribute to the accurate segregation of homologs at the first meiotic division. Chromosome morphogenesis and the molecular processes of recombination are intimately linked at all stages of the recombination process, although the underlying mechanisms of these links are not fully understood.

Recombination is initiated by programmed DNA double-strand break (DSB) formation by the topoisomerase VI-like Spo11 protein together with a number of protein partners (Lam and Keeney 2014; Robert et al. 2016). DSB formation takes place when sister chromatids are condensed into an array of chromatin loops anchored at their bases to the chromosome axis (Zickler and Kleckner 1999). The axis comprises several proteins, including the cohesin complex containing at least one meiosis-specific kleisin subunit, Rec8, and the proteins that will later form the lateral element of the synaptonemal complex (SC) (e.g. Red1 and Hop1 in budding yeast and SYCP2 and SYCP3 in mammals). An intriguing feature of meiotic recombination is that DSB formation occurs in chromatin loop sequences located distal from the protein axis, whereas proteins required for DSB formation are located on the chromosome axis (Blat et al. 2002; Pan et al. 2011; Panizza et al. 2011). This has led to the proposal that DSB-prone sequences transiently interact with the chromosome axis as a prerequisite for cleavage by Spo11 (Blat et al. 2002; Miyoshi et al. 2012; Panizza et al. 2011). The chromosome axis is believed to play a role in controlling DSB numbers and distribution through the activities of the Tel1 ${ }^{\text {ATM }}$ kinase (Cooper et al. 2016; Garcia et al. 2015; Joyce et al. 2011; Lange et al. 2016; Mohibullah and Keeney 2017; Zhang et al. 2011). It also plays a role in the repair template choice, i.e., whether the sister chromatid or a chromatid of the homolog is the template for repair. This role is exerted through in particular the local action of the axis-associated Mek1 kinase, which phosphorylates proteins involved in inhibiting inter-sister recombination and favoring interhomolog repair of meiotic DSBs (Callender et al. 2016; Hollingsworth and Gaglione 2019; Humphryes and Hochwagen 2014).

After Spo11 removal and DSB 5' end resection by Mre11 and Exo1 proteins (Cannavo and Cejka 2014; Garcia et al. 2011; Mimitou et al. 2017; Neale et al. 2005; Zakharyevich et al. 2010), strand invasion takes place and a D-loop is formed, which is a common intermediate to all types of meiotic DSB repair (Bishop and Zickler 2004) (Figure 1). D- 
loop formation is highly dynamic and reversible due to perpetual conflicts between activities that promote and inhibit DNA strand invasion (De Muyt et al. 2012). Noncrossovers (NCOs) can be formed by synthesis-dependent strand annealing (SDSA) when the D-loop is dismantled after DNA synthesis has extended the invading strand (Allers and Lichten 2001; Hunter and Kleckner 2001). The newly synthesized end then anneals to the 3' end on the other side of the DSB to repair the break without an exchange of chromosome arms (Figure 1). Alternatively, DNA synthesis extends the D-loop region, thereby providing a single stranded site for annealing of the DSB second end, a process referred to as second-end capture (Lao et al. 2008). Ligation of DNA ends leads to the formation of a double Holliday junction (dHJ) (Schwacha and Kleckner 1995) which may after cleavage give rise to either a $\mathrm{NCO}$ or a $\mathrm{CO}$, depending on the cleavage orientation of each Holliday junction (Figure 1). The factors that control the fate of a D-loop intermediate to give a $\mathrm{NCO}$ or a $\mathrm{CO}$ have been well described and mostly result from two opposite activities that are well conserved during evolution: dismantling of the intermediate by a helicase (the Sgs1-Top3-Rmi1 (STR) complex in S. cerevisiae) or stabilization by a group of proteins referred to as "the ZMMs" (an acronym for Zip1-4, Msh4-5, Mer3, Spo16) (Börner et al. 2004; Jessop et al. 2006; Kaur et al. 2015; Oh et al. 2007; Tang et al. 2015). In budding yeast, most of D-loops stabilized by ZMMs are processed as COs. However, ZMM foci outnumber the COs in several other species, suggesting that the D-loops bound by ZMM proteins are not exclusively processed as COs and can still form NCOs (De Muyt et al. 2014; Edelmann et al. 1999; Higgins et al. 2008) (Figure 1). In addition, a minor fraction of the formed D-loops escapes these two pathways, and forms joint molecules that can be cleaved as COs or NCOs by the structurespecific nucleases (SSN), Mus81/Yen1/Slx1 (De Muyt et al. 2012; Zakharyevich et al. 2012) (Figure 1). ZMM-dependent COs rarely form in close vicinity of each other and are more evenly spaced than would be expected from a random distribution (Muller 1916), reviewed in (Berchowitz and Copenhaver 2010). These COs are referred to as interfering or "type I" crossovers. They represent the major fraction, ranging from 75 to $100 \%$ of the totality of crossovers (Figure 1). By contrast, crossovers produced by the SSNs do not show interference, and are called "type II" crossovers.

\section{The canonical budding yeast " $\mathrm{zmm}$ " phenotype}

In the absence of ZMM genes in budding yeast, less SEI and $\mathrm{dHJ}$ intermediates are formed, meiotic progression is delayed, spore viability is decreased and fewer COs occur at least 
when recombination is monitored at hotspots along yeast chromosome III (Börner et al. et al. 2004). The COs occurring in these mutants are non-interfering and depend on the SSNs (Argueso et al. 2004; de los Santos et al. 2003; Novak et al. 2001; Shinohara et al. 2008; Sym and Roeder 1994). However, the original phenotype of $z m m$ mutants has evolved with the use of other approaches that led to the discovery of feedback mechanisms that increase the frequency of DSBs and some effects varying with chromosome size (see below).

According to genetic and molecular studies, the mechanism of action of ZMM begins after DNA strand invasion (Figure 1) (Börner et al. 2004). Binding of ZMMs is proposed to stabilize D-loops and convert them into a more stable intermediate called single-end invasion (SEI) that can be detected on two-dimensional gels (Hunter and Kleckner 2001). This intermediate is the precursor of COs. This stabilized intermediate is then processed into a protected $\mathrm{dHJ}$ that will be exclusively resolved as a $\mathrm{CO}$ by the endonuclease activity of the Mutly (Mlh1-Mlh3) complex (Nishant et al. 2008; Zakharyevich et al. 2012).

It is difficult to estimate accurately $\mathrm{CO}$ frequencies in zmm mutants genetically, since their spore viability is reduced, selecting for those events that resulted in viable spores. Using genome-wide approaches in budding yeast hybrids, several studies found a reduction of COs ranging from 34 to $60 \%$ (one exception was for the zip1A, see below), and confirmed that the COs were non-interfering (Chen et al. 2008; Mancera et al. 2008; MarsolierKergoat et al. 2018; Oke et al. 2014; Sym and Roeder 1994). However, the reduction in COs is not equal on all chromosomes and varies depending on chromosome size. Accordingly, COs are more reduced on small chromosomes (such as chromosome III) than on large chromosomes (such as chromosome VIII), where CO frequencies in certain zmm mutants may exceed those observed in the wild type (Chen et al. 2015; Serrentino et al. 2013). One hypothesis is that failure to synapse results in continued Spo11 activity disproportionately increasing DSBs along larger chromosomes (Keeney et al. 2014; Subramanian et al. 2019; Thacker et al. 2014). Approximately half of these breaks can be repaired as COs via the SSNs and they differ from ZMM COs in that they do not interfere. Therefore, caution is needed when analyzing CO frequencies on only one chromosome since the effects can vary according to chromosome size. By contrast, NCO numbers are not decreased in zmm mutants, but actually increased, which may be due to a combination of feedback mechanisms that increase DSB frequency in response to the defect in 
homologous chromosomes juxtaposition and an increase in the SDSA pathway promoted 2014; Thacker et al. 2014).

In addition to their recombination function, all ZMM proteins are required to promote synaptonemal complex formation in budding yeast, but not in plants and, for some cases, in the mouse (Adelman and Petrini 2008; Chelysheva et al. 2007; de Vries et al. 1999; Edelmann et al. 1999; Guiraldelli et al. 2018; Higgins et al. 2004; Higgins et al. 2008; Hunter 2015; Kneitz et al. 2000; Macaisne et al. 2008; Mercier et al. 2005; Mercier et al. 2015; Shen et al. 2012; Shinohara et al. 2008; Wang et al. 2009; Yang et al. 2008; Zhang et al. 2014b; Zhang et al. 2019; Zhang et al. 2018b).

\section{The ZMM group of proteins: roles and known molecular functions}

It becomes clear that ZMM proteins do not work independently on early steps of meiotic recombination but form subcomplexes that recognize particular DNA structures and act collectively, probably through transient protein-protein interactions, to shape DNA branched molecules and form the appropriate precursor cleaved by the Mutl $\gamma$ complex to make an interfering CO. In addition, the stabilization of CO precursors by ZMMs is connected to SC dynamics and, as suggested by fungal and mouse studies, ZMM proteins help to bring chromosomes axes closer together and start SC polymerization. Furthermore, direct protein-protein interactions are being uncovered between ZMM and components of the SC.

\section{- The synaptonemal complex transverse filament Zip1}

The budding yeast Zip1 protein is a coiled-coil protein with two terminal globular domains, which forms the transverse filaments that span the central region of the SC. Zip1 is required for synapsis (Sym et al. 1993; Tung and Roeder 1998). No Zip1 protein can be identified in other organisms by simple sequence homology analysis, underlining the high divergence of SC proteins during evolution (Fraune et al. 2016; Gao and Colaiacovo 2018; Page and Hawley 2004). However, transverse filament proteins in many organisms share structural similarities with Zip1, including a long coiled-coil domain flanked by globular domains, as well as the localization to the central region of the SC. These proteins include SYCP1 in mammals, ZEP1 in rice, two closely related proteins ZYP1a and ZYP1b in $A$. thaliana, SYP-1 and SYP-2 in C. elegans, C(3)G in D. melanogaster and Sme4/Zip1 in Sordaria (Colaiácovo et al. 2003; de Vries et al. 2005; Espagne et al. 2011; Higgins et al. 
2005; Meuwissen et al. 1992; Page and Hawley 2001; Wang et al. 2010) (Table 1). In these both synapsis and normal crossover formation (Colaiácovo et al. 2003; de Vries et al. 2005; Espagne et al. 2011; Higgins et al. 2005; MacQueen et al. 2002; Page and Hawley 2001), indicating that the "ZMM" function of Zip1 is mostly conserved. Within the polymerized SC, Zip1 is in the form of head-to-head dimers that assemble in a ladder-like structure with the N-termini in the center of the SC and the C-termini associated with the axes of the homologous partners (Dong and Roeder 2000).

It was initially thought that Zip1 would play a "late" role among the ZMM proteins because all ZMMs are necessary for SC polymerization in budding yeast (Agarwal and Roeder 2000; Chua and Roeder 1998; Shinohara et al. 2008; Tsubouchi et al. 2006). Consistently, zip1D seems less affected than the other $\mathrm{zmm}$ for formation of the SEI and $\mathrm{dHJ}$ intermediates, although their formation is strongly delayed (Börner et al. 2004). Moreover, ZMM proteins still localize on chromosomes in the absence of Zip1 relatives in the mouse, rice and Sordaria, suggesting a later function of Zip1 and its relatives (de Vries et al. 2005; Espagne et al. 2011; Wang et al. 2010). However, recent studies in budding yeast suggest that Zip1 has an early role during $\mathrm{CO}$ biochemistry by triggering, right after being recruited to the DSBs, the other ZMM assembly/activation. For instance, the localization of Zip3, another ZMM, to DSB sites is dependent on ZIP1 (Serrentino et al. 2013), and in several $\mathrm{zmm}$ mutants, Zip1 shows residual loading to chromosomes as seen by immunostaining, but with a dotty pattern (Agarwal and Roeder 2000; Chen et al. 2015; Chua and Roeder 1998; Shinohara et al. 2008; Storlazzi et al. 1996; Tsubouchi et al. 2006) (Figure 2a).

Zip1 is recruited to chromosomes via its C-terminal region requiring DSB formation (Henderson and Keeney 2004; Tung and Roeder 1998). The Zip1 C-terminus is then phosphorylated after DSB formation by the DDK (DBF4-dependent kinase) cell cycle kinase and this phosphorylation is required for crossover recombination (Chen et al. 2015). After its recruitment presumably to DSB sites, Zip1 phosphorylation would create a patch of negative charges that helps promote its interaction with other ZMM proteins (Chen et al. 2015), including Zip2 and Zip3 to form the "synapsis initiation complex" (SIC) (Fung et al. 2004). The resulting SIC then initiates SC polymerization to allow synapsis. This function may be conserved, since the C-terminal region of Zip1 phosphorylated in yeast is conserved in species that use recombination for synapsis like yeast and mice 
(Chen et al. 2015). Interestingly, recent analyses showed that although Zip1 is necessary to promote $Z M M$-dependent crossovers, its polymerization into the SC is not. A K. Lactis yeast version of ZIP1 used to replace the S. cerevisiae ZIP1 is not able to form SC, but complements zip14 for crossover recombination, albeit with reduced interference (Voelkel-Meiman et al. 2015). Furthermore, the region of S. cerevisiae Zip1 important for SC and synapsis but not crossover resides in the 21 to 162 residues region (VoelkelMeiman et al. 2016). Thus, Zip1 seems to have separable functions: one early to assemble a proper and functional set of ZMM proteins at recombination sites (Chen et al. 2015), and the other one later to elongate the synaptonemal complex (Voelkel-Meiman et al. 2016).

○ The D-loop binding Mer3 helicase

The MER3 gene was discovered in budding yeast as a mutant defective in meiotic recombination and encodes a DNA helicase with a 3' to 5' polarity (Nakagawa et al. 2001; Nakagawa and Ogawa 1999). Mer3 has orthologs in other fungi, in plants and mammals, and its inactivation leads to a similar $\mathrm{CO}$ and, with the exception of plants, synapsis defect as in budding yeast, indicating that its function is mostly conserved (Guiraldelli et al. 2013; Mercier et al. 2005; Storlazzi et al. 2010; Wang et al. 2009) (Table 1). Furthermore, hfm1 (the mammalian name for MER3) mutations are found in human patients with azoospermia or primary ovarian insufficiency syndromes, illustrating its essential role for human fertility (Wang et al. 2014; Zhang et al. 2017).

The genetic dependencies for Mer3 association with meiotic chromosomes have not been fully determined. However, although mer3 mutants clearly have a " $\mathrm{zmm}$ " phenotype, there are several indications that it associates to DSB sites early in the recombination process. First, in Sordaria, Mer3 localizes as pairs of foci already at the leptotene stage, with one focus on each homolog, suggesting that Mer3 binds the two DSB ends, or the two sides of a recombination intermediate (Storlazzi et al. 2010). In addition, Mer3 focus numbers, where examined, are much higher than the observed CO numbers (Chen et al. 2005; Rao et al. 2017; Storlazzi et al. 2010; Wang et al. 2009). Finally, a role of MER3, independent of its role in crossover formation, was recently described, which affects DNA synthesis during $\mathrm{CO}$ and NCO formation (Duroc et al. 2017). In budding yeast, Mer3 specifically interacts with and recruits a mismatch repair-related heterodimer, MutL $\beta$ (Mlh1-Mlh2 in budding yeast, MLH1-PMS1 in mammals) to recombination hotspots, to limit the extension of recombination intermediates by DNA synthesis, and thus the length of gene conversion tracts (Duroc et al. 2017). Strikingly, this function is independent of Mer3's 
helicase activity and does not influence CO frequency (Duroc et al. 2017). In accordance that are formed early during recombination (Duroc et al. 2017). The Mer3/MutL $\beta$ interaction seems conserved in the mouse as shown by two-hybrid interaction between HFM1 and MutL $\beta$ (Duroc et al. 2017). The fact that MutL $\beta$ is "linked" to the ZMM pathway is illustrated by a study that examined the gains and losses of ZMM proteins during yeast evolution (Vakirlis et al. 2016). Strikingly, Mlh2 was lost concomitantly with the ZMM proteins in the Lachancea budding yeast clade, consistent with a functional connection between them (Vakirlis et al. 2016). Intriguingly, MutL $\beta$ is absent from plants genomes, although plants have the Mer3 protein (Campbell et al. 2014). Therefore, it is not clear if the function of MutL $\beta$ is taken over by another actor in these organisms. The biological meaning of limiting the extent of DNA synthesis at recombination sites is not known, but it may have an evolutionary advantage in preserving ancestral allelic combinations from extensive gene conversion (Duroc et al. 2017).

Mer3 is able to unwind D-loops, Holliday junctions and substrates with a 3' overhang in vitro (Duroc et al. 2017; Nakagawa et al. 2001; Nakagawa and Kolodner 2002a). It was further shown that Mer3 is able to stimulate Rad51-mediated strand exchange activity and D-loop extension in the direction opposite to DNA synthesis (Mazina et al. 2004). This in vitro function might in vivo stabilize the nascent recombination intermediates into a more stable intermediate, which would correspond to the SEI, specific to the ZMM crossover pathway (Börner et al. 2004; Hunter and Kleckner 2001; Mazina et al. 2004) (Figure 1). However, Mer3 helicase activity is only partly responsible for Mer3's ZMM function, since a helicase-dead mutant is less affected for meiotic progression, spore viability and crossover frequency than a null mutant (Duroc et al. 2017; Nakagawa and Kolodner 2002b; Storlazzi et al. 2010). It is possible that Mer3's binding to D-loops is sufficient to stabilize them and allow stronger subsequent or parallel stabilization by the other ZMMs (see below). The helicase activity would only reinforce this stabilization. In rice, MER3 localization on chromosomes is dependent of the ZMM proteins ZIP4 and MSH4, suggesting that it needs other members of the ZMM group to be recruited or stabilized (Shen et al. 2012; Zhang et al. 2014b). However, no physical interactions with other ZMM proteins have been described (Figure $2 \mathrm{~b}$ ). Mer3 is therefore not in a stable complex with other ZMMs, but may interact with them only transiently.

\section{○ The Zip2-Zip4-Spo16 “ZZS” complex}


ZIP2, ZIP4 and SPO16 had been inferred to work collectively to promote the formation of Tsubouchi et al. 2006). Recently, these proteins have been shown to form a functional complex (ZZS, for Zip2-Zip4-ㅁppo16) (De Muyt et al. 2018). Within this complex, Zip2 and Spo16 share homology with the XPF/ERCC1 family of structure-selective endonucleases, although Zip2 does not contain the canonical motif required for endonuclease activity of most XPF domain proteins (Arora and Corbett 2019; De Muyt et al. 2018; Macaisne et al. 2008). Consistently, the Zip2 XPF domain, in complex with Spo16, lacks endonuclease activity towards branched DNA molecules in vitro (De Muyt et al. 2018). However, the Zip2 XPF domain is required for ZZS pro-CO activity, and the Zip2 XPF-Spo16 subcomplex binds preferentially DNA branched structures (D-loops and Holliday junctions), suggesting that it acts as a recognition module to attract the whole ZZS complex at specific joint molecules that will be prone to be converted into CO (Arora and Corbett 2019; De Muyt et al. 2018).

Zip4 is a large TPR (tetratricopeptide repeat) protein (Perry et al. 2005; Tsubouchi et al. 2006). TPR motifs are known to mediate protein-protein interaction and the assembly of multiprotein complexes (D'Andrea and Regan 2003). Consistent with this inference, Zip4 is proposed to coordinate several meiotic processes by acting as a hub through physical interactions with components of the chromosome axis (Red1 and Hop1) and other ZMMs (Zip3 and Msh4-5) (De Muyt et al. 2018). In addition, Zip4 is important for Zip2 protein stability, suggesting that Zip4 might also work as a chaperone besides its function as a scaffold protein (De Muyt et al. 2018).

The Zip2 and Zip4 orthologs, mZIP2/SHOC1 and TEX11/AtZIP4, have been identified in mammals and plants, respectively, and are required for normal levels of interfering COs and fertility, suggesting the conservation of this function of the ZZS complex (Table 1) (Adelman and Petrini 2008; Chelysheva et al. 2007; Guiraldelli et al. 2018; Macaisne et al. 2008; Shen et al. 2012; Yang et al. 2008). Interestingly, mutations in the TEX11 gene in humans is associated with non-obstructive azoospermia, suggesting the importance of the ZZS complex for CO formation and human fertility (Sha et al. 2018; Yang et al. 2015; Yatsenko et al. 2015). In Arabidopsis, the ERCC1-like protein PTD interacts with the XPF domain protein SHOC1 and is required for meiotic COs, suggesting that a Zip2-Spo16 equivalent might be present in plants (Macaisne et al. 2011; Wijeratne et al. 2006). A Spo16/PTD-relative has recently been identified in the mouse. mSpo16 $\%$ mice are sterile 
and show a strong reduction of MLH1 foci and SYCP1 signal, suggesting a role of mSP016 in CO and SC assembly and a conservation of the entire ZZS complex between yeast, plants and mammals (Zhang et al. 2019) .

\section{○ The Zip3 and HEI10 E3 ligases}

DNA repair processes are coordinated by multiple post-translational modifications, including SUMOylation (Psakhye and Jentsch 2012). This may also be the case during meiotic recombination, since SUMOylation/ubiquitylation has been observed along chromosome axes during prophase I of meiosis in yeast, fungi, worm and mouse (Bhalla et al. 2008; De Muyt et al. 2014; Hooker and Roeder 2006; Rao et al. 2017). In addition, the budding yeast E3 ligase Zip3, potentially involved in SUMOylation/ubiquitylation, is one of the ZMM proteins (Agarwal and Roeder 2000). Zip3 is recruited right after DSB processing by the DNA damage response complex 9-1-1 and further stabilized on recombination intermediates after strand invasion (Serrentino et al. 2013; Shinohara et al. 2015). ZIP3 is required for the association of other ZMM proteins to chromosomes and for SC elongation (Figure 2a) (Shinohara et al. 2008). Zip3, like the other E3 ligases, possesses a C3HC4 zinc finger RING domain, which is required for Zip3 E3 SUMO ligase activity in vitro (Cheng et al. 2006). This domain generally promotes protein interactions to recruit E2 conjugating enzymes to transfer ubiquitin/SUMO to its ultimate target and provides substrates specificity (Kerscher et al. 2006). In budding yeast, this domain is required for Zip3 binding to chromosomes, meiotic progression and SC polymerization, indicating that post-translational modifications carried out by Zip3 E3 ligase are important for meiotic recombination/chromosome structure processes (Cheng et al. 2006; Serrentino et al. 2013).

Zip3 orthologs have been discovered in other organisms and it emerges that two subgroups exist within the Zip3 family: the Zip3/RNF212 group and the HEI10 group (Chelysheva et al. 2012; De Muyt et al. 2014) (Table 1). Plants, fungi, C. elegans and Drosophila possess a single RNF212 or HEI10 ortholog (Bhalla et al. 2008; Chelysheva et al. 2012; De Muyt et al. 2014; Jantsch et al. 2004; Lake et al. 2015; Wang et al. 2012), whereas vertebrates encode separate RNF212 and HEI10 proteins that function as antagonistic SUMO and ubiquitin E3 ligases, respectively (Gray and Cohen 2016; Qiao et al. 2014; Rao et al. 2017; Reynolds et al. 2013; Ward et al. 2007). Moreover, the presence of several Zip3-related proteins within the same organism, for instance the mammalian RNF212 ortholog (RNF212B), provides an additional layer of complexity in the 
recombination control by E3-ligase activities (Kong et al. 2008; Reynolds et al. 2013). four RING finger E3 ligase proteins, ZHP-1, ZHP-2, ZHP-3 and ZHP-4 that act together to promote a spatio-temporal accumulation of pro-CO factors (Nguyen et al. 2018; Zhang et al. 2018b).

The function of ZIP3-like genes can differ between species. For instance, the Zip3-related Vilya, beyond its role in crossover formation, participates in DSB fate determination in Drosophila female by interacting directly with Mei-P22, a DSB protein partner of Spo11, and is required for DSB formation (Lake et al. 2015). The role of ZIP3-like genes can vary between genders. In mouse, RNF212 is involved in a female-specific mechanism of prefollicle quality control that guides oocytes with unrepaired DNA damage towards apoptotic pathways (Qiao et al. 2018).

The biochemical distinction between Ubiquitin and SUMO E3 ligases is difficult. Therefore, it remains unclear what the exact enzymatic activity of the Zip3 family is. Zip3/RNF212 group members appear to act solely as SUMO E3 ligases, from biochemical and genetic studies performed in budding yeast and C. elegans (Bhalla et al. 2008; Cheng et al. 2006). By contrast, some members of the HEI10 group appear to possess ubiquitin E3 ligase activity (Toby et al. 2003), even if studies suggest that mouse HEI10 may also function as a SUMO E3 ligase (Strong and Schimenti 2010).

The function of Zip3-mediated SUMO/ubiquitin post-translational modification is also obscure. One possible mechanism might be to locally SUMOylate proteins, which would act like a glue to consolidate multiple interactions between partners and help to promote CO at DSB repair sites (De Muyt et al. 2018; De Muyt et al. 2014). Such a role for Zip3 and its relatives would be consistent with the presence of recombination nodules at recombination sites, visible by electron microscopy as highly dense chromosome structures (Zickler and Kleckner 1999), which might reflect a high concentration of DNA repair/pro-CO proteins as was described for the progressive accumulation of HEI10 proteins observed at the future CO sites (Chelysheva et al. 2012; De Muyt et al. 2014; Qiao et al. 2014). In addition, it was suggested that Zip1 associates with SUMO conjugates (e.g. Red1) in order to form the SC (Cheng et al. 2006).

Direct SUMO/ubiquitin targets of the Zip3 family have not been identified. Yeast Zip3 interacts with Zip1, ZZS members (Zip2 and Zip4) and the ZMM Msh4 (Figure 2b) (Agarwal and Roeder 2000; De Muyt et al. 2018), suggesting that CO formation may occur 
via post-translational modification of the ZMM proteins. Consistently, it has been specific recombination factors, such as the ZMM MSH4-MSH5 (MutSy) heterodimer, on recombining meiotic chromosomes via a SUMO-ubiquitin relay, which would promote subsequent recruitment of the proteins involved in crossover formation, including MLH1MLH3 (MutLy) (Gray and Cohen 2016; Qiao et al. 2014; Rao et al. 2017; Reynolds et al. 2013; Ward et al. 2007). Similarly, rice HEI10 can interact with MSH5, suggesting that a similar mechanism occurs in plants. These observations suggest that the relationship between SUMOylation and ubiquitylation of proteins at recombination sites progressively determines which DSBs become competent for CO (Qiao et al. 2014).

\section{$\circ \quad$ The MutS $\gamma$ Msh4-Msh5 heterodimer}

Msh4 and Msh5, two other ZMMs, share homology with DNA mismatch recognition factor MutS of the bacterial mismatch repair (MMR) and form the MutS $\gamma$ heterodimer (Hollingsworth et al. 1995; Pochart et al. 1997; Ross-Macdonald and Roeder 1994). Msh4 and Msh5 are conserved among fungi, plants and mammals, and are also present in the worm C. elegans (Table 1). Msh4 and Msh5 exhibit structural homology with four of the five domains of MutS homolog proteins, including the ATP-binding motif and the heterodimerization domain, but lack the first domain critical for DNA mismatch binding and have no role in MMR (Manhart and Alani 2016). In mice, MutS $\gamma$ is essential for chromosomal synapsis, crossover formation and thus fertility, the null mutant mouse being sterile (de Vries et al. 1999; Kneitz et al. 2000). In Arabidopsis and rice, null mutants of MutSy homologs also have decreased fertility and less crossovers, and chromosome synapsis is slightly affected (Higgins et al. 2004; Higgins et al. 2008; Zhang et al. 2014b). In C. elegans, the ortholog of Msh4, HIM-14, and MSH-5 play a critical role in CO formation (Kelly et al. 2000; Zalevsky et al. 1999). In Sordaria, Msh4 plays a role in chromosome recognition and pairing, thus before its supposed role in the recombination process (Storlazzi et al. 2010). The human recombinant heterodimer specifically binds D-loops and Holliday junctions in vitro. After DNA binding, MSH4-MSH5 is converted into a sliding clamp in an ATP-dependent manner, which diffuses away from the junction while embracing two homologous DNA-duplex arms (Snowden et al. 2004). A recent study in $C$. elegans showed that two MSH-5 doublets are present at CO sites (Woglar and Villeneuve 2018). Although this result needs biochemical support, it suggests that two populations of MutS $\gamma$ complexes encircle and accumulate on each DNA duplex located in the interval 
between the two Holliday junctions (Figure 3). The binding and stabilization of dHJs by Sgs1/BLM (Jessop et al. 2006; Oh et al. 2007). In addition to this "ZMM" function, it has been proposed, by homology to the MMR, that MutS $\gamma$ recruits and activates the CO-biased JM resolving heterodimer MutL $\gamma$ in order to favor the resolution of the stabilized $\mathrm{dHJs}$ in a CO (Gray and Cohen 2016). In support of this hypothesis, MSH4-MSH5 interacts with MutL $\gamma$ in mice testes (Santucci-Darmanin et al. 2002).

Strikingly, as seen by cytology in Sordaria, C. elegans, plants and the mouse, the initial number of MutS $\gamma$ foci is greater than the final number of crossovers and most foci are lost during prophase while the remaining MutS $\gamma$ foci correspond to future CO sites (De Muyt et al. 2014; de Vries et al. 1999; Edelmann et al. 1999; Higgins et al. 2008; Kneitz et al. 2000; Yokoo et al. 2012; Zhang et al. 2014b). The removal of Msh4-Msh5 depends on the ZMM ZHP-1/2/RNF212/HEI10 E3 ligases protein family (Qiao et al. 2014; Reynolds et al. 2013; Zhang et al. 2018a). In mice, it has been suggested that the balance of RNF212mediated SUMOylation and HEI10-mediated ubiquitylation determines the stability of MutS $\gamma$ complex by protecting it from proteolysis at CO-specific DNA intermediates (Qiao et al. 2014). Interestingly, a recent study in budding yeast indicates that another type of post-translational modification is important for MutS $\gamma$ complex stability (He et al. 2018). This study showed that MutS $\gamma$ is intrinsically unstable, unless its N-terminal degron sequence is phosphorylated by DDK. The phosphorylation-defective msh4-6A mutant retains the chromosome binding function and is only mildly affected for SEI and $\mathrm{dHJ}$ formation and synapsis. However, CO numbers in $m s h 4-6 A$ strain are reduced like in the $m s h 4 \Delta$ mutant while NCO numbers are not. Therefore, phosphorylation of Msh4 could ensure the protection of dHJs against Sgs1-Top3-Rmi1 activity and favor their biased resolution towards COs versus NCOs. In a proposed model, sliding clamps of MutS $\gamma$ would need to accumulate above a threshold in order to facilitate COs, which is only possible when Msh4 is stabilized by phosphorylation (He et al. 2018). When not stabilized by phosphorylation, MutS $\gamma$ is lost from recombination sites, due to the abundance of SCassociated proteasomes (Ahuja et al. 2017; Rao et al. 2017). Msh4 phosphorylation by DDK observed in budding yeast may be conserved among other organisms, and consequently the regulation pathway of crossover formation, since the DDK consensus $\mathrm{S} / \mathrm{T}$ enriched region is conserved in all Msh4 homologs (He et al. 2018). 


\section{New additions to the ZMM group}

So far, the ZMM group comprises eight proteins (or protein family for the E3 ligases Zip3 and HEI10 relatives) that direct the fate of recombination intermediates towards COs. However, other proteins with pro-CO activity have been recently identified that could also be considered as members of the ZMM group. Besides its role in centromere pairing, the budding yeast phosphatase PP4 (Pph3/Psy2) is important for joint molecule stability (SEIs and dHJs) and for CO formation, possibly by antagonizing the checkpoint kinase Mec1ATR_dependent phosphorylation of the N-terminal region of Zip1 (Falk et al. 2010). Also in budding yeast, the alpha 3 subunit of the proteasome's core particle, Pre9, has been identified through a screen for transposon insertion mutations that conferred a temperature-dependent defect in spore formation, like zmm mutants (Ahuja et al. 2017). pre $9 \Delta$ possesses features of a zmm mutant, as defined by the reduction of CO level due to the inability to stabilize SEIs and by the reduction of SC formation (Ahuja et al. 2017). This function of the proteasome seems evolutionary conserved, since components of the proteasome are observed on meiotic chromosomes in budding yeast, but also in mouse and C. elegans (Ahuja et al. 2017; Rao et al. 2017). It has been proposed that the proteasome is recruited to the chromosome axis and regulates the turnover of recombination factors, including the ZMMs HFM1/Mer3 and TEX11/Zip4, through HEI10mediated ubiquitylation (Rao et al. 2017).

Interestingly, the HEI10 protein might not work alone during ubiquitylation processes. In plants, the newly identified HEI10-interacting protein, HEIP1, is necessary for the formation of interfering COs and colocalizes with the site of COs represented by late HEI10 foci (Li et al. 2018). Besides its interaction with HEI10, HEIP1 interacts with both ZIP4 and MSH5, suggesting that this new putative ZMM member may regulate CO formation by bridging multiple pro-CO factors in order to modify them by ubiquitin activities and progressively shape meiotic recombination intermediates towards the proCO state (Li et al. 2018). Similarly, the Tetrahymena protein Sa15 interacts with Zhp3, the Zip3 ortholog, and is required for wild-type CO levels and localizes to meiotic chromosomes (Shodhan et al. 2017). However, this protein has no conserved domain and does not seem to be evolutionarily conserved.

ZMM proteins influence SC formation, and the SC per se is not strictly required for ZMM-dependent $\mathrm{CO}$ formation, but influences their distribution 
During early meiotic prophase, meiotic recombination and SC assembly are temporally and spatially closely associated. In several organisms, including budding yeast, plants, Sordaria and mice, normal SC assembly requires initiation of meiotic recombination and Rad51/Dmc1-mediated stable strand exchange activity (Baudat et al. 2000; Cahoon and Hawley 2016; De Muyt et al. 2009; Espagne et al. 2011; Henderson and Keeney 2004; Mercier et al. 2015; Pittman et al. 1998; Romanienko and Camerini-Otero 2000; Vignard et al. 2007; Yoshida et al. 1998). ZMM proteins also participate in SC elongation. The presence of ZMM proteins on chromosome axes might reflect their early loading at the time when DSBs are processed towards CO-competent DNA intermediates, as it is observed by the early recruitment of Zip3 and Mer3 to chromosome axes in budding yeast and Sordaria, respectively, or by the physical interaction between Zip4/TEX11 and axis components, Red1 and SYCP2, in yeast and mouse, respectively (De Muyt et al. 2018; Serrentino et al. 2013; Storlazzi et al. 2010; Yang et al. 2008).

In budding yeast and Sordaria zmm mutants, axial elements are formed normally but the central region fails to polymerize normally at the leptotene-zygotene transition (Börner et al. 2004; Espagne et al. 2011; Storlazzi et al. 2010). Interestingly, zmm mutants can be distinguished according to their ability to polymerize the SC. The absence of ZIP2, ZIP4 or SPO16 abolishes SC assembly in budding yeast, while in the lack of MutS $\gamma$ (MSH4-MSH5) or ZIP3, SC is incomplete but not absent (Agarwal and Roeder 2000; Börner et al. 2004; Chua and Roeder 1998; Humphryes et al. 2013; Novak et al. 2001; Tsubouchi et al. 2006). Functions of ZMM proteins for normal SC assembly have also been observed in other organisms. In the mouse, the chromosome axes form normally in mutants lacking Hfm1/Mer3, Msh4 or Msh5, but the SC central element SYCP1 fails to assemble correctly (de Vries et al. 1999; Edelmann et al. 1999; Guiraldelli et al. 2013; Kneitz et al. 2000). Curiously, Tex11\% and hypomorph Shoc1/Mzip2\% mutant mice lacking intact ZIP4 and ZIP2-relatives, respectively, show a much less severe phenotype as shown by normal synapsis and nearly wild type levels of MLH1 foci (which mark CO sites) (Adelman and Petrini 2008; Guiraldelli et al. 2018; Yang et al. 2008). However, a recent report found a strong decrease in MLH1 foci and synapsis defects in a Mzip2-null mouse, suggesting that the role of SHOC1/MZIP2, and possibly TEX11, for CO formation and SC assembly has been underestimated (Zhang et al. 2018b). By contrast, the Zip3-relatives, RNF212 and HEI10, are not important for synapsis despite being required for CO formation (De Muyt et al. 2014; Reynolds et al. 2013; Ward et al. 2007). In plants, SC polymerization relies on 
the production of interhomolog recombination intermediates but not on the ZMM both zip4 and mer3 mutations, suggesting that these ZMM genes might have redundant roles for SC loading in plants (Shen et al. 2012).

Early studies in several organisms suggested correlations between CO and sites of synapsis initiation (Maguire 1972; Nur 1968; Stack and Soulliere 1984). More recent analyses in budding yeast support this hypothesis by showing that the number of interstitial SC initiation sites corresponds well to CO numbers (Agarwal and Roeder 2000; Henderson and Keeney 2004; Tsubouchi et al. 2006; Zickler 2006). However, in other organisms such as the mouse, plants and Sordaria, there are more ZMM foci than CO numbers (De Muyt et al. 2014; Edelmann et al. 1999; Higgins et al. 2008). In Sordaria, SC nucleation seems to occur both at $\mathrm{CO}$ sites and at a subset of other recombination sites that are matured to NCOs, despite initial loading by ZMM proteins (Zhang et al. 2014a). Thus, recombination intermediates may be reversed to NCO products after ZMM loading, possibly at a later step than initial D-loop formation (as shown in Figure 1), that may involve a dissolution activity of recombination intermediates by helicase complex such as STR. In both cases, SC initiation sites often colocalize with ZMM proteins and decrease in number in mutants with decreased CO numbers, suggesting that SC formation starts at sites where ZMMs nucleate, also called SICs (for "Synapsis Initiation Complex") (Tsubouchi et al. 2006). The specific pattern of ZMM/SC installation is dependent on DSB numbers. In hypomorphic spo11 mutants of budding yeast, there are only a few Zip3 foci, from where only partial SC elongation occurs (Henderson and Keeney 2004). Similarly, in mouse or Sordaria, few SC initiation sites and incomplete polymerization are observed when DSBs are reduced, suggesting that a minimum number of nucleation of ZMM/SC formation sites is required for full homolog synapsis (Kauppi et al. 2013; Tessé et al. 2017; Tessé et al. 2003). These nucleation sites are suggested to be sites for a crosstalk between ZMM proteins, chromosome axis juxtaposition and SC polymerization (Zhang et al. 2014b). Consistent with this inference, localization studies in Sordaria suggest that ZMM components (at least Zip2, Zip4, Mer3 and Msh4) would help to bring "miniatures axes", known as bridges, from the parental chromosome axes into the inter-axis region (Dubois et al. 2019) (see below) (Figure 3). SC installation would then nucleate at these sites of parental bridges when bridges reach a length of precisely $100 \mathrm{~nm}$, which corresponds to the space between homologs during synapsis. 
Although per se, the SC is not required for interfering COs, several pieces of evidence yeast, the absence of the SC central element proteins, Ecm11 and Gmc2, or of the Nterminal domain (21-163) of Zip1 does not have apparent meiotic defects, as suggested by wild-type spore viability (Humphryes et al. 2013). However, these mutants show increased $\mathrm{CO}$ frequency on certain chromosomes, although COs are still dependent on MSH4, suggesting that the SC plays an inhibitory role that limits ZMM-dependent CO formation (Voelkel-Meiman et al. 2016). Likewise, decrease of the transverse filament protein in rice and $C$. elegans results in an increase of $\mathrm{CO}$ markers and an attenuation of CO interference indicating that negative regulation of interfering $\mathrm{CO}$ by the $\mathrm{SC}$ is conserved (Hayashi et al. 2010; Libuda et al. 2013; Wang et al. 2010). The mechanism behind this control remains unclear. It is possible that the SC central element somehow promotes $\mathrm{CO}$ interference. An alternative explanation could be that higher $\mathrm{CO}$ frequency might be partly due to the formation of de novo DSBs when homologous chromosomes fail to correctly synapse (Kauppi et al. 2013; Thacker et al. 2014).

\section{Integrated functions of ZMM proteins in promoting and coordinating crossover formation and synapsis}

Distinct protein-protein interactions and biochemical activities identified among ZMM proteins suggest that they work at different steps of CO maturation, namely D-loop stabilization (step a, Figure 3), SEI formation (step b, Figure 3), second-end capture and $\mathrm{dHJ}$ stabilization (step c, Figure 3). We therefore propose the following integrated model for their action. In budding yeast, an epistatic study made between zip1-4A mutant and the other ZMMs suggested that Zip1 is one of the earliest pro-CO factors to act during meiotic recombination, possibly by recruiting other ZMMs through the acidic patch resulting from DDK-dependent phosphorylation of the Zip1 C-terminus (Chen et al. 2015). The ZZS complex and Mer3 might be recruited to DSB sites in a Zip1-dependent manner. Indeed, genetic, biochemical and cytological studies suggest that these proteins are recruited early to DSBs sites, presumably during D-loop formation (De Muyt et al. 2018; Duroc et al. 2017; Storlazzi et al. 2010), to perform two distinct biochemical activities: the ZZS complex directly binds branched DNA molecules, through its XPF-ERCC1-like domain (De Muyt et al. 2018), while the helicase Mer3 binds D-loops, and promotes heteroduplex extension in a 3' to 5' polarity (in the opposite direction to DNA synthesis), resulting in D- 
loop stabilization (Mazina et al. 2004; Nakagawa and Kolodner 2002a) (Figure 3a). The antagonize the anti-recombination effect of STR. In budding yeast, the E3 ligase Zip3 interacts with the ZZS complex and is important for the recruitment of most of the ZMM proteins (Figure 2b), suggesting that it also acts early on D-loops by stabilizing newly recruited ZMM proteins presumably via SUMO/Ubiquitin post-translational modifications (Figure 3a).

Meanwhile, the ZZS complex, in particular Zip4, interacts with the SC axial element component, Red1 (Figure 2b). One attractive possibility is that the physical association between the ZZS complex and Red1 could bring closer together the parental chromosomes axes during the homology search and the binding of recombination intermediates by ZMMs. In this model, the mechanical imprinting provided by the transit of the axis-associated ZZS complex from the parental chromosome axes into the inter-axis region would lead to the formation of chromosomes axis bridges that progressively align and tether parental chromosomes (Figure 3(i)). This hypothesis would fit well with the observation that the ZZS complex co-purifies with the axial component Red1, although it does not strongly associate with the DNA attached to the axis (De Muyt et al. 2018).

The Msh4-Msh5 heterodimer interacts directly with DNA and exhibits biochemical activities that could promote or stabilize stable strand invasion by forming a sliding clamp on recombination intermediates (Snowden et al. 2004). Although the prediction of the cavity size formed by the Msh4-Msh5 heterodimer suggests that it is large enough to embrace a whole unfolded Holliday junction (Rakshambikai et al. 2013), recent highresolution cytological studies in $C$. elegans are compatible with the MutS $\gamma$ complex binding only one heteroduplex DNA at a time (Woglar and Villeneuve 2018) (Figure 3bc). Msh4-Msh5 and ZZS complexes bind independently from each other to chromosomes (De Muyt et al. 2018; Shinohara et al. 2008) (Figure 2a). However, the physical interaction observed between Zip4 and Msh5 suggests that these complexes, probably along with Mer3, act synergistically on DNA intermediates to promote stable SEI intermediate formation (Figure 3b-c). During this process, SEI will be progressively stabilized by the MutS $\gamma$ heterodimer and the phosphorylation of Msh4 protein (He et al. 2018). The physical link observed between Zip3 and the MutS $\gamma$ complex suggests that Zip3 consolidates the mechanism of CO maturation by further stabilizing this complex (Agarwal and Roeder 2000) (Figure 2b). 
Msh5, like Zip4, physically interacts with the axis protein Red1 in budding yeast (De Muyt region of the SC in Sordaria (Storlazzi et al. 2010), suggesting that Msh4-Msh5 heterodimer could act in concert with the ZZS complex to bring chromosome axes at a $100 \mathrm{~nm}$ distance, which allows initiation of the central region of the SC polymerization. Based on cytological and molecular results, Tsubouchi and colleagues proposed a mechanism of polymerization of the SC from SIC sites, in which the central element Ecm11-Gmc2 complex is recruited to SIC sites and facilitates, along with the SIC, the initial polymerization of Zip1 (Humphryes et al. 2013) (Figure 3(i)). This Zip1 assembly along the chromosomes is then consolidated by the SUMOylation of Ecm11 protein, independently of the Zip3 SUMO ligase activity (but dependent of both E3 ligases Siz1 and Siz2) (Leung et al. 2015).

During the SEI-to-dHJ transition, the displaced 3' strand of an SEI undergoes annealing to the second DSB end (Lao et al. 2008) (Figure 3c). Interestingly, in the zip3 $\Delta$ mutant gene conversion tracts associated with COs are slightly longer, which may result from a defect in the second-end capture (Oke et al. 2014). In addition, the interaction observed between Zip4 and Zip3 suggests that the ZZS complex could cooperate with Zip3 in this process, possibly by interacting and stabilizing DNA branched molecules that are formed during this post-invasion step of meiotic DSBs repair (De Muyt et al. 2018)(Figure 3c). After dHJ formation, the SC is fully polymerized along the parental chromosomes, forming the characteristic tripartite structure visible by electron microscopy (Figure 3(ii)). Finally, in budding yeast, the exit from pachytene stage is controlled by Ndt80, a transcription factor that activates transcription of the $C D C 5$ polo-like kinase, which triggers both resolution of dHJs as interfering COs by the Mutl $\gamma$ complex (Mlh1-Mlh3) and SC breakdown (Prugar et al. 2017; Sourirajan and Lichten 2008), leading to homologous chromosomes that are only linked by COs and sister chromatid cohesion (Figure 3d).

\section{Perspectives}

By means of many studies performed in multiple organisms, our understanding of the role of ZMM proteins during homologous recombination has greatly improved. Still, several important points about ZMM functions remain to be clarified: 
(i) The biochemical activities of ZMM proteins are still poorly understood, in particular their roles, synergistic or not, to shape early recombination intermediates toward CO fate or their antagonistic interplay with the Sgs1-Top3-Rmi1 anti-recombination activities.

(ii) The identification of new pro-CO proteins, such as HEI10 or HEIP1, indicates that the number of actors required for formation of interfering COs is still increasing and calls for further exploration of not yet-identified pro-CO genes.

(iii) Even though there is significant evidence that ZMM proteins play a predominant role in SC formation in budding yeast, Sordaria and, to a lesser extent, in the mouse, the molecular mechanism that coordinates $\mathrm{CO}$ and SC formation remains to be elucidated. Moreover, both the assembly and disassembly of the SC is likely achieved through multiple layers of regulation (Gao and Colaiacovo 2018). Therefore, it will be important to determine what governs the coordination between SC dynamics and the homologous recombination process.

(iv) Interference between COs implies the existence of a signal along the chromosome that disfavors the appearance of a second $\mathrm{CO}$ if a $\mathrm{CO}$ is already formed nearby. The absence of ZMM results in non-interfering COs, whereas the absence of SC central element proteins influences the distribution of interfering $\mathrm{CO}$. It is not clear whether the coupling between SC assembly and CO formation plays a role in CO interference and how this connection could be integrated with the implementation CO interference by DNA topology (Zhang et al. 2014c).

In conclusion, further investigation of the ZMM-dependent $\mathrm{CO}$ formation and its relationship with the SC dynamics in different model organisms will be needed to uncover both their conserved as well as distinct features and reveal how it could impact human fertility. The identification of causal genetic variants by whole genome/exome sequencing and their association to diseases or disorders is a rapidly growing field. The combination with molecular studies of recombination proteins should help to identify the regions or nucleotides of genes that are critical for fertility and might improve diagnosis of sterile patients. Reciprocally, the emergence of new genome editing technologies will open new areas to test candidate variants and improve our understanding of the molecular function of recombination proteins, including ZMMs.

\section{Acknowledgements}


We thank Nancy Hollingsworth, Denise Zickler and Wayne Crismani for critical reading of

the manuscript. Work in the V.B. lab is funded by Institut Curie, CNRS, Labex DEEP (ANR11-LBX-0044), ANR (ANR-15-CE11-0011), Projet Fondation ARC, La Ligue contre le Cancer and Electricité de France. A. P. is funded by a doctoral fellowship from PSL University.

\section{References}

Adelman CA, Petrini JH (2008) ZIP4H (TEX11) deficiency in the mouse impairs meiotic double strand break repair and the regulation of crossing over. PLoS Genetics 4:e1000042

Agarwal S, Roeder GS (2000) Zip3 provides a link between recombination enzymes and synaptonemal complex proteins. Cell 102:245-255

Ahuja JS et al. (2017) Control of meiotic pairing and recombination by chromosomally tethered $26 \mathrm{~S}$ proteasome. Science 355:408-411

Albini SM, Jones GH (1987) Synaptonemal complex spreading in Allium cepa and $A$. fistulosum. I: The initiation and sequence of pairing. Chromosoma 95:324-338

Allers T, Lichten M (2001) Differential timing and control of noncrossover and crossover recombination during meiosis. Cell 106:47-57

Argueso JL, Wanat J, Gemici Z, Alani E (2004) Competing crossover pathways act during meiosis in Saccharomyces cerevisiae. Genetics 168:1805-1816

Arora K, Corbett KD (2019) The conserved XPF:ERCC1-like Zip2:Spo16 complex controls meiotic crossover formation through structure-specific DNA binding. Nucleic Acids Res 47:2365-2376

Baudat F, Manova K, Yuen JP, Jasin M, Keeney S (2000) Chromosome synapsis defects and sexually dimorphic meiotic progression in mice lacking Spo11. Mol Cell 6:989-998

Berchowitz LE, Copenhaver GP (2010) Genetic interference: don't stand so close to me. Curr Genomics 11:91-102

Bhalla N, Wynne DJ, Jantsch V, Dernburg AF (2008) ZHP-3 acts at crossovers to couple meiotic recombination with synaptonemal complex disassembly and bivalent formation in C. elegans. PLoS Genetics 4:e1000235

Bishop DK, Zickler D (2004) Early decision; meiotic crossover interference prior to stable strand exchange and synapsis. Cell 117:9-15

Blat Y, Protacio RU, Hunter N, Kleckner N (2002) Physical and functional interactions among basic chromosome organizational features govern early steps of meiotic chiasma formation. Cell 111:791-802

Börner GV, Kleckner N, Hunter N (2004) Crossover/noncrossover differentiation, synaptonemal complex formation, and regulatory surveillance at the leptotene/zygotene transition of meiosis. Cell 117:29-45

Cahoon CK, Hawley RS (2016) Regulating the construction and demolition of the synaptonemal complex. Nature Structural \& Molecular Biology 23:369-377

Callender TL et al. (2016) Mek1 Down Regulates Rad51 Activity during Yeast Meiosis by Phosphorylation of Hed1. PLoS Genetics 12:e1006226

Campbell CS et al. (2014) Mlh2 is an accessory factor for DNA mismatch repair in Saccharomyces cerevisiae. PLoS Genetics 10:e1004327 
Cannavo E, Cejka P (2014) Sae2 promotes dsDNA endonuclease activity within Mre11Rad50-Xrs2 to resect DNA breaks. Nature 514:122-125

Chelysheva L, Gendrot G, Vezon D, Doutriaux MP, Mercier R, Grelon M (2007) Zip4/Spo22 is required for class I CO formation but not for synapsis completion in Arabidopsis thaliana. PLoS Genetics 3:e83

Chelysheva L et al. (2012) The Arabidopsis HEI10 Is a New ZMM Protein Related to Zip3. PLoS Genetics 8:e1002799

Chen C, Zhang W, Timofejeva L, Gerardin Y, Ma H (2005) The Arabidopsis ROCK-N-ROLLERS gene encodes a homolog of the yeast ATP-dependent DNA helicase MER3 and is required for normal meiotic crossover formation. Plant Journal 43:321-334

Chen SY et al. (2008) Global analysis of the meiotic crossover landscape. Developmental Cell 15:401-415

Chen X et al. (2015) Phosphorylation of the Synaptonemal Complex Protein Zip1 Regulates the Crossover/Noncrossover Decision during Yeast Meiosis. PLoS Biology 13:e1002329

Cheng CH et al. (2006) SUMO modifications control assembly of synaptonemal complex and polycomplex in meiosis of Saccharomyces cerevisiae. Genes \& development 20:20672081

Chua PR, Roeder GS (1998) Zip2, a meiosis-specific protein required for the initiation of chromosome synapsis. Cell 93:349-359

Colaiácovo MP, MacQueen AJ, Martinez-Perez E, McDonald K, Adamo A, La Volpe A, Villeneuve AM (2003) Synaptonemal Complex Assembly in C. elegans Is Dispensable for Loading Strand-Exchange Proteins but Critical for Proper Completion of Recombination. Developmental Cell 5:463-474

Cooper TJ, Garcia V, Neale MJ (2016) Meiotic DSB patterning: A multifaceted process. Cell Cycle 15:13-21

D'Andrea L, Regan L (2003) TPR proteins: the versatile helix. Trends in Biochemical Sciences 28:655-662

de los Santos T, Hunter N, Lee C, Larkin B, Loidl J, Hollingsworth NM (2003) The Mus81/Mms4 endonuclease acts independently of double-Holliday junction resolution to promote a distinct subset of crossovers during meiosis in budding yeast. Genetics 164:81-94

De Muyt A, Jessop L, Kolar E, Sourirajan A, Chen J, Dayani Y, Lichten M (2012) BLM helicase ortholog Sgs1 is a central regulator of meiotic recombination intermediate metabolism. Molecular Cell 46:43-53

De Muyt A et al. (2009) A high throughput genetic screen identifies new early meiotic recombination functions in Arabidopsis thaliana. PLoS genetics 5:e1000654

De Muyt A et al. (2018) A meiotic XPF-ERCC1-like complex recognizes joint molecule recombination intermediates to promote crossover formation. Genes \& development 32:283-296

De Muyt A, Zhang L, Piolot T, Kleckner N, Espagne E, Zickler D (2014) E3 ligase Hei10: a multifaceted structure-based signaling molecule with roles within and beyond meiosis. Genes \& development 28:1111-1123

de Vries FAT et al. (2005) Mouse Sycp1 functions in synaptonemal complex assembly, meiotic recombination, and XY body formation. Genes \& development 19:1376-1389 
de Vries SS, Baart EB, Dekker M, Siezen A, Rooij DGd, Boer Pd, Riele Ht (1999) Mouse MutSlike protein Msh5 is required for proper chromosome synapsis in male and female meiosis. Genes \& development 13:523-531

del Cacho E, Pages M, Gallego M, Monteagudo L, Sánchez-Acedo C (2005) Synaptonemal complex karyotype of Eimeria tenella. International Journal for Parasitology 35:14451451

Dong H, Roeder GS (2000) Organization of the yeast Zip1 protein within the central region of the synaptonemal complex. The Journal of Cell Biology 148:417-426

Dubois E et al. (2019) Building bridges to move recombination complexes. Proc Natl Acad Sci USA

Duroc $Y$ et al. (2017) Concerted action of the MutLbeta heterodimer and Mer3 helicase regulates the global extent of meiotic gene conversion. Elife 6:e21900

Edelmann W et al. (1999) Mammalian MutS homologue 5 is required for chromosome pairing in meiosis. Nature Genetics 21:123-127

Espagne E, Vasnier C, Storlazzi A, Kleckner NE, Silar P, Zickler D, Malagnac F (2011) Sme4 coiled-coil protein mediates synaptonemal complex assembly, recombinosome relocalization, and spindle pole body morphogenesis. Proceedings of the National Academy of Sciences of the United States of America 108:10614-10619

Falk JE, Chan AC, Hoffmann E, Hochwagen A (2010) A Mec1- and PP4-dependent checkpoint couples centromere pairing to meiotic recombination. Developmental Cell 19:599611

Fraune J, Brochier-Armanet C, Alsheimer M, Volff JN, Schucker K, Benavente R (2016) Evolutionary history of the mammalian synaptonemal complex. Chromosoma 125:355-360

Fung JC, Rockmill B, Odell M, Roeder GS (2004) Imposition of crossover interference through the nonrandom distribution of synapsis initiation complexes. Cell 116:795-802

Gao J, Colaiacovo MP (2018) Zipping and Unzipping: Protein Modifications Regulating Synaptonemal Complex Dynamics. Trends in Genetics 34:232-245

Garcia V, Gray S, Allison RM, Cooper TJ, Neale MJ (2015) Tel1(ATM)-mediated interference suppresses clustered meiotic double-strand-break formation. Nature 520:114-118

Garcia V, Phelps SE, Gray S, Neale MJ (2011) Bidirectional resection of DNA double-strand breaks by Mre11 and Exo1. Nature 479:241-244

Gray S, Cohen PE (2016) Control of Meiotic Crossovers: From Double-Strand Break Formation to Designation. Annual Review of Genetics 50:175-210

Guiraldelli MF, Eyster C, Wilkerson JL, Dresser ME, Pezza RJ (2013) Mouse HFM1/Mer3 is required for crossover formation and complete synapsis of homologous chromosomes during meiosis. PloS Genetics 9:e1003383

Guiraldelli MF, Felberg A, Almeida LP, Parikh A, Castro ROd, Pezza RJ (2018) SHOC1 is a ERCC4-(HhH)2-like protein, integral to the formation of crossover recombination intermediates during mammalian meiosis. PLoS Genetics 14:e1007381

Hayashi M, Mlynarczyk-Evans S, Villeneuve AM (2010) The synaptonemal complex shapes the crossover landscape through cooperative assembly, crossover promotion and crossover inhibition during Caenorhabditis elegans meiosis. Genetics 186:45-58

He W et al. (2018) The crossover function of MutSy is activated via Cdc7-dependent stabilization of Msh4. BioRxiv 
Henderson KA, Keeney S (2004) Tying synaptonemal complex initiation to the formation and programmed repair of DNA double-strand breaks. Proceedings of the National Academy of Sciences of the United States of America 101:4519-4524

Higgins JD, Armstrong SJ, Franklin FCH, Jones GH (2004) The Arabidopsis MutS homolog AtMSH4 functions at an early step in recombination: evidence for two classes of recombination in Arabidopsis. Genes \& development 18:2557-2570

Higgins JD, Sanchez-Moran E, Armstrong SJ, Jones GH, Franklin FCH (2005) The Arabidopsis synaptonemal complex protein ZYP1 is required for chromosome synapsis and normal fidelity of crossing over. Genes \& development 19:2488-2500

Higgins JD, Vignard J, Mercier R, Pugh AG, Franklin FCH, Jones GH (2008) AtMSH5 partners AtMSH4 in the class I meiotic crossover pathway in Arabidopsis thaliana, but is not required for synapsis. The Plant Journal 55:28-39

Hollingsworth NM, Gaglione R (2019) The meiotic-specific Mek1 kinase in budding yeast regulates interhomolog recombination and coordinates meiotic progression with double-strand break repair. Curr Genet

Hollingsworth NM, Ponte L (1997) Genetic interactions between HOP1, RED1 and MEK1 suggest that MEK1 regulates assembly of axial element components during meiosis in the yeast Saccharomyces cerevisiae. Genetics 147:33-42

Hollingsworth NM, Ponte L, Halsey C (1995) MSH5, a novel MutS homolog, facilitates meiotic reciprocal recombination between homologs in Saccharomyces cerevisiae but not mismatch repair. Genes \& development 9:1728-1739

Hooker GW, Roeder GS (2006) A Role for SUMO in Meiotic Chromosome Synapsis. Curr Biol 16:1238-1243

Humphryes N, Hochwagen A (2014) A non-sister act: recombination template choice during meiosis. Experimental Cell Research 329:53-60

Humphryes N, Leung WK, Argunhan B, Terentyev Y, Dvorackova M, Tsubouchi H (2013) The Ecm11-Gmc2 complex promotes synaptonemal complex formation through assembly of transverse filaments in budding yeast. PloS Genetics 9:e1003194

Hunter N (2015) Meiotic Recombination: The Essence of Heredity. In: Cold Spring Harb Perspect Biol. doi:10.1101/cshperspect.a016618

Hunter N, Kleckner N (2001) The single-end invasion: an asymmetric intermediate at the double-strand break to double-holliday junction transition of meiotic recombination. Cell 106:59-70

Jantsch V, Pasierbek P, Mueller MM, Schweizer D, Jantsch M, Loidl J (2004) Targeted Gene Knockout Reveals a Role in Meiotic Recombination for ZHP-3, a Zip3-Related Protein in Caenorhabditis elegans. Molecular and Cellular Biology 24:7998-8006

Jessop L, Rockmill B, Roeder GS, Lichten M (2006) Meiotic chromosome synapsis-promoting proteins antagonize the anti-crossover activity of Sgs1. PLoS Genetics 2:e155

Joyce EF, Pedersen M, Tiong S, White-Brown SK, Paul A, Campbell SD, McKim KS (2011) Drosophila ATM and ATR have distinct activities in the regulation of meiotic DNA damage and repair. J Cell Biol 195:359-367

Kauppi L, Barchi M, Lange J, Baudat F, Jasin M, Keeney S (2013) Numerical constraints and feedback control of double-strand breaks in mouse meiosis. Genes \& development 27:873-886

Kaur H, De Muyt A, Lichten M (2015) Top3-Rmi1 DNA Single-Strand Decatenase Is Integral to the Formation and Resolution of Meiotic Recombination Intermediates. Molecular Cell 57:583-594 
Keeney S, Lange J, Mohibullah N (2014) Self-organization of meiotic recombination initiation: general principles and molecular pathways. Annu Rev Genet 48:187-214

Kelly KO, Dernburg AF, Stanfield GM, Villeneuve AM (2000) Caenorhabditis elegans msh-5 is required for both normal and radiation-induced meiotic crossing over but not for completion of meiosis. Genetics 156:617-630

Kerscher O, Felberbaum R, Hochstrasser M (2006) Modification of Proteins by Ubiquitin and Ubiquitin-Like Proteins. Annual Review of Cell and Developmental Biology 22:159180

Kneitz B et al. (2000) MutS homolog 4 localization to meiotic chromosomes is required for chromosome pairing during meiosis in male and female mice. Genes \& development 14:1085-1097

Kong A et al. (2008) Sequence Variants in the RNF212 Gene Associate with Genome-Wide Recombination Rate. Science 319:1398-1401

Lake CM, Nielsen RJ, Guo F, Unruh JR, Slaughter BD, Hawley RS (2015) Vilya, a component of the recombination nodule, is required for meiotic double-strand break formation in Drosophila. elife 4:e08287

Lam I, Keeney S (2014) Mechanism and regulation of meiotic recombination initiation. Cold Spring Harb Perspect Biol 7:a016634

Lange J et al. (2016) The Landscape of Mouse Meiotic Double-Strand Break Formation, Processing, and Repair. Cell 167:695-708 e616

Lao JP, Oh SD, Shinohara M, Shinohara A, Hunter N (2008) Rad52 promotes postinvasion steps of meiotic double-strand-break repair. Molecular Cell 29:517-524

Leung W-K, Humphryes N, Afshar N, Argunhan B, Terentyev Y, Tsubouchi T, Tsubouchi H (2015) The synaptonemal complex is assembled by a polySUMOylation-driven feedback mechanism in yeast. The Journal of Cell Biology 211:785-793

Li Y et al. (2018) HEIP1 regulates crossover formation during meiosis in rice. Proceedings of the National Academy of Sciences of the United States of America 115:10810-10815

Libuda DE, Uzawa S, Meyer BJ, Villeneuve AM (2013) Meiotic chromosome structures constrain and respond to designation of crossover sites. Nature 502:703-706

Macaisne $\mathrm{N}$ et al. (2008) SHOC1, an XPF endonuclease-related protein, is essential for the formation of class I meiotic crossovers. Curr Biol 18:1432-1437

Macaisne N, Vignard J, Mercier R (2011) SHOC1 and PTD form an XPF-ERCC1-like complex that is required for formation of class I crossovers. J Cell Sci 124:2687-2691

MacQueen AJ, Colaiacovo MP, McDonald K, Villeneuve AM (2002) Synapsis-dependent and independent mechanisms stabilize homolog pairing during meiotic prophase in $C$. elegans. Genes \& development 16:2428-2442

Maguire MP (1972) The temporal sequence of synaptic initiation, crossing over and synaptic completion. Genetics 70:353-370

Mancera E, Bourgon R, Brozzi A, Huber W, Steinmetz LM (2008) High-resolution mapping of meiotic crossovers and non-crossovers in yeast. Nature 454:479-485

Manhart CM, Alani E (2016) Roles for mismatch repair family proteins in promoting meiotic crossing over. DNA Repair (Amst) 38:84-93

Marsolier-Kergoat MC, Khan MM, Schott J, Zhu X, Llorente B (2018) Mechanistic View and Genetic Control of DNA Recombination during Meiosis. Molecular Cell 70:9-20 e26

Mazina OM, Mazin AV, Nakagawa T, Kolodner RD, Kowalczykowski SC (2004) Saccharomyces cerevisiae Mer3 helicase stimulates 3'-5' heteroduplex extension by Rad51; implications for crossover control in meiotic recombination. Cell 117:47-56 
Mercier R et al. (2005) Two meiotic crossover classes cohabit in Arabidopsis: one is dependent on MER3, whereas the other one is not. Curr Biol 15:692-701

Mercier R, Mézard C, Jenczewski E, Macaisne N, Grelon M (2015) The Molecular Biology of Meiosis in Plants. Annual Review of Plant Biology 66:297-327

Meuwissen RL, Offenberg HH, Dietrich AJ, Riesewijk A, van lersel M, Heyting C (1992) A coiled-coil related protein specific for synapsed regions of meiotic prophase chromosomes. EMBO J 11:5091-5100

Mimitou EP, Yamada S, Keeney S (2017) A global view of meiotic double-strand break end resection. Science 355:40-45

Miyoshi T et al. (2012) A Central Coupler for Recombination Initiation Linking Chromosome Architecture to S Phase Checkpoint. Mol Cell 47:722-733

Mohibullah N, Keeney S (2017) Numerical and spatial patterning of yeast meiotic DNA breaks by Tel1. Genome Res 27:278-288

Muller HJ (1916) The mechanism of crossing over. Am Nat 50:193-434

Nakagawa T, Flores-Rozas $\mathrm{H}$, Kolodner RD (2001) The MER3 helicase involved in meiotic crossing over is stimulated by single-stranded DNA-binding proteins and unwinds DNA in the 3 ' to 5 ' direction. J Biol Chem 276:31487-31493

Nakagawa T, Kolodner RD (2002a) The MER3 DNA helicase catalyzes the unwinding of holliday junctions. J Biol Chem 277:28019-28024

Nakagawa T, Kolodner RD (2002b) Saccharomyces cerevisiae Mer3 is a DNA helicase involved in meiotic crossing over. Molecular and Cellular Biology 22:3281-3291

Nakagawa T, Ogawa H (1999) The Saccharomyces cerevisiae MER3 gene, encoding a novel helicase-like protein, is required for crossover control in meiosis. EMBO J 18:57145723

Neale MJ, Pan J, Keeney S (2005) Endonucleolytic processing of covalent protein-linked DNA double-strand breaks. Nature 436:1053-1057

Nguyen H, Labella S, Silva N, Jantsch V, Zetka M (2018) C. elegans ZHP-4 is required at multiple distinct steps in the formation of crossovers and their transition to segregation competent chiasmata. PLoS Genetics 14:e1007776

Nishant KT, Chen C, Shinohara M, Shinohara A, Alani E (2010) Genetic analysis of baker's yeast Msh4-Msh5 reveals a threshold crossover level for meiotic viability. PLoS Genetics 6:e1001083

Nishant KT, Plys AJ, Alani E (2008) A mutation in the putative MLH3 endonuclease domain confers a defect in both mismatch repair and meiosis in Saccharomyces cerevisiae. Genetics 179:747-755

Novak JE, Ross-Macdonald PB, Roeder GS (2001) The budding yeast Msh4 protein functions in chromosome synapsis and the regulation of crossover distribution. Genetics 158:1013-1025

Nur U (1968) Synapsis and crossing over within a paracentric inversion in the grasshopper, Camnula pellucida. Chromosoma 25:198-214

Oh SD, Lao JP, Hwang PY, Taylor AF, Smith GR, Hunter N (2007) BLM ortholog, Sgs1, prevents aberrant crossing-over by suppressing formation of multichromatid joint molecules. Cell 130:259-272

Oke A, Anderson CM, Yam P, Fung JC (2014) Controlling Meiotic Recombinational Repair Specifying the Roles of ZMMs, Sgs1 and Mus81/Mms4 in Crossover Formation. PLoS Genetics 10:e1004690 
Page SL, Hawley RS (2001) c(3)G encodes a Drosophila synaptonemal complex protein. Genes \& development 15:3130-3143

Page SL, Hawley RS (2004) The Genetics and Molecular Biology of the Synaptonemal Complex. Annual Review of Cell and Developmental Biology 20:525-558

Pan J et al. (2011) A hierarchical combination of factors shapes the genome-wide topography of yeast meiotic recombination initiation. Cell 144:719-731

Panizza S, Mendoza MA, Berlinger M, Huang L, Nicolas A, Shirahige K, Klein F (2011) Spo11accessory proteins link double-strand break sites to the chromosome axis in early meiotic recombination. Cell 146:372-383

Perry J, Kleckner N, Borner GV (2005) Bioinformatic analyses implicate the collaborating meiotic crossover/chiasma proteins Zip2, Zip3, and Spo22/Zip4 in ubiquitin labeling. Proceedings of the National Academy of Sciences of the United States of America 102:17594-17599

Pittman DL et al. (1998) Meiotic prophase arrest with failure of chromosome synapsis in mice deficient for Dmc1, a germline-specific RecA homolog. Mol Cell 1:697-705

Pochart P, Woltering D, Hollingsworth NM (1997) Conserved properties between functionally distinct MutS homologs in yeast. J Biol Chem 272:30345-30349

Prugar E, Burnett C, Chen X, Hollingsworth NM (2017) Coordination of Double Strand Break Repair and Meiotic Progression in Yeast by a Mek1-Ndt80 Negative Feedback Loop. Genetics 206:497-512

Psakhye I, Jentsch S (2012) Protein Group Modification and Synergy in the SUMO Pathway as Exemplified in DNA Repair. Cell 151:807-820

Qiao $\mathrm{H}$ et al. (2014) Antagonistic roles of ubiquitin ligase HEI10 and SUMO ligase RNF212 regulate meiotic recombination. Nature Genetics 46:194-199

Qiao H et al. (2018) Impeding DNA Break Repair Enables Oocyte Quality Control. Molecular Cell 72:211-221.e213

Rakshambikai R, Srinivasan N, Nishant KT (2013) Structural Insights into Saccharomyces cerevisiae Msh4-Msh5 Complex Function Using Homology Modeling. PLoS ONE 8:e78753

Rao HBDP et al. (2017) A SUMO-ubiquitin relay recruits proteasomes to chromosome axes to regulate meiotic recombination. Science 355:403-407

Reynolds A et al. (2013) RNF212 is a dosage-sensitive regulator of crossing-over during mammalian meiosis. Nature Genetics 45:269-278

Robert T, Vrielynck N, Mezard C, de Massy B, Grelon M (2016) A new light on the meiotic DSB catalytic complex. Semin Cell Dev Biol 54:165-176

Romanienko PJ, Camerini-Otero RD (2000) The mouse Spo11 gene is required for meiotic chromosome synapsis. Mol Cell 6:975-987

Ross-Macdonald P, Roeder GS (1994) Mutation of a meiosis-specific MutS homolog decreases crossing over but not mismatch correction. Cell 79:1069-1080

Santucci-Darmanin S, Neyton S, Lespinasse F, Saunieres A, Gaudray P, Paquis-Flucklinger V (2002) The DNA mismatch-repair MLH3 protein interacts with MSH4 in meiotic cells, supporting a role for this MutL homolog in mammalian meiotic recombination. Human molecular genetics 11:1697-1706

Schwacha A, Kleckner N (1995) Identification of double Holliday junctions as intermediates in meiotic recombination. Cell 83:783-791

Serrentino ME, Borde V (2012) The spatial regulation of meiotic recombination hotspots: Are all DSB hotspots crossover hotspots? Experimental Cell Research 318:1347-1352 
Serrentino ME, Chaplais E, Sommermeyer V, Borde V (2013) Differential association of the conserved SUMO ligase Zip3 with meiotic double-strand break sites reveals regional variations in the outcome of meiotic recombination. PloS Genetics 9:e1003416

Sha $Y$ et al. (2018) A novel TEX11 mutation induces azoospermia: a case report of infertile brothers and literature review. BMC Medical Genetics 19:63

Shen Y et al. (2012) ZIP4 in homologous chromosome synapsis and crossover formation in rice meiosis. J Cell Sci 125:2581-2591

Shinohara M, Hayashihara K, Grubb JT, Bishop DK, Shinohara A (2015) DNA damage response clamp 9-1-1 promotes assembly of ZMM proteins for formation of crossovers and synaptonemal complex. J Cell Sci 128:1494-1506

Shinohara M, Oh SD, Hunter N, Shinohara A (2008) Crossover assurance and crossover interference are distinctly regulated by the ZMM proteins during yeast meiosis. Nature Genetics 40:299-309

Shodhan A, Kataoka K, Mochizuki K, Novatchkova M, Loidl J (2017) A Zip3-like protein plays a role in crossover formation in the SC-less meiosis of the protist Tetrahymena. Molecular Biology of the Cell 28:825-833

Snowden T, Acharya S, Butz C, Berardini M, Fishel R (2004) hMSH4-hMSH5 recognizes Holliday Junctions and forms a meiosis-specific sliding clamp that embraces homologous chromosomes. Molecular Cell 15:437-451

Sourirajan A, Lichten M (2008) Polo-like kinase Cdc5 drives exit from pachytene during budding yeast meiosis. Genes \& development 22:2627-2632

Stack SM, Soulliere DL (1984) The relation between synapsis and chiasma formation in Rhoeo spathacea. Chromosoma 90:72-83

Storlazzi A, Gargano S, Ruprich-Robert G, Falque M, David M, Kleckner N, Zickler D (2010) Recombination proteins mediate meiotic spatial chromosome organization and pairing. Cell 141:94-106

Storlazzi A, Xu L, Schwacha A, Kleckner N (1996) Synaptonemal complex (SC) component Zip1 plays a role in meiotic recombination independent of SC polymerization along the chromosomes. Proc Natl Acad Sci U S A 93:9043-9048

Strong ER, Schimenti JC (2010) Evidence Implicating CCNB1IP1, a RING Domain-Containing Protein Required for Meiotic Crossing Over in Mice, as an E3 SUMO Ligase. Genes $1: 440-451$

Subramanian VV et al. (2019) Persistent DNA-break potential near telomeres increases initiation of meiotic recombination on short chromosomes. Nat Commun 10:970

Sym M, Engebrecht JA, Roeder GS (1993) ZIP1 is a synaptonemal complex protein required for meiotic chromosome synapsis. Cell 72:365-378

Sym M, Roeder GS (1994) Crossover interference is abolished in the absence of a synaptonemal complex protein. Cell 79:283-292

Tang S, Wu Michelle Ka Y, Zhang R, Hunter N (2015) Pervasive and Essential Roles of the Top3-Rmi1 Decatenase Orchestrate Recombination and Facilitate Chromosome Segregation in Meiosis. Molecular Cell 57:607-621

Tessé S et al. (2017) Asy2/Mer2: an evolutionarily conserved mediator of meiotic recombination, pairing, and global chromosome compaction. Genes \& development 31:1880-1893

Tessé S, Storlazzi A, Kleckner N, Gargano S, Zickler D (2003) Localization and roles of Ski8p protein in Sordaria meiosis and delineation of three mechanistically distinct steps of 
meiotic homolog juxtaposition. Proceedings of the National Academy of Sciences of the United States of America 100:12865-12870

Thacker D, Mohibullah N, Zhu X, Keeney S (2014) Homologue engagement controls meiotic DNA break number and distribution. Nature 510:241-246

Toby GG, Gherraby W, Coleman TR, Golemis EA (2003) A novel RING finger protein, human enhancer of invasion 10, alters mitotic progression through regulation of cyclin $B$ levels. Molecular and Cellular Biology 23:2109-2122

Tsubouchi T, Zhao H, Roeder GS (2006) The meiosis-specific Zip4 protein regulates crossover distribution by promoting synaptonemal complex formation together with Zip2. Developmental Cell 10:809-819

Tung K-S, Roeder GS (1998) Meiotic chromosome morphology and behavior in zip1 mutants of Saccharomyces cerevisiae. Genetics 149:817-832

Vakirlis $\mathrm{N}$ et al. (2016) Reconstruction of ancestral chromosome architecture and gene repertoire reveals principles of genome evolution in a model yeast genus. Genome Research 26:918-932

Vignard J et al. (2007) The interplay of RecA-related proteins and the MND1-HOP2 complex during meiosis in Arabidopsis thaliana. PLoS Genet 3:1894-1906

Voelkel-Meiman K, Cheng S-Y, Morehouse SJ, MacQueen AJ (2016) Synaptonemal Complex Proteins of Budding Yeast Define Reciprocal Roles in MutSY-Mediated Crossover Formation. Genetics 203:1091-1103

Voelkel-Meiman K, Johnston C, Thappeta Y, Subramanian VV, Hochwagen A, MacQueen AJ (2015) Separable Crossover-Promoting and Crossover-Constraining Aspects of Zip1 Activity during Budding Yeast Meiosis. PLOS Genetics 11:e1005335

Wang J, Zhang W, Jiang H, Wu BL, Primary Ovarian Insufficiency C (2014) Mutations in HFM1 in recessive primary ovarian insufficiency. N Engl J Med 370:972-974

Wang K et al. (2009) MER3 is required for normal meiotic crossover formation, but not for presynaptic alignment in rice. J Cell Sci 122:2055-2063

Wang K et al. (2012) The Role of Rice HEl10 in the Formation of Meiotic Crossovers. PLoS Genetics 8:e1002809

Wang M et al. (2010) The Central Element Protein ZEP1 of the Synaptonemal Complex Regulates the Number of Crossovers during Meiosis in Rice. The Plant Cell 22:417430

Ward JO et al. (2007) Mutation in mouse hei10, an e3 ubiquitin ligase, disrupts meiotic crossing over. PLoS Genetics 3:e139

Wijeratne AJ, Chen C, Zhang W, Timofejeva L, Ma H (2006) The Arabidopsis thaliana PARTING DANCERS gene encoding a novel protein is required for normal meiotic homologous recombination. Molecular Biology of the Cell 17:1331-1343

Woglar A, Villeneuve AM (2018) Dynamic Architecture of DNA Repair Complexes and the Synaptonemal Complex at Sites of Meiotic Recombination. Cell 173:1678-1691 e1616

Woltering D, Baumgartner B, Bagchi S, Larkin B, Loidl J, de los Santos T, Hollingsworth NM (2000) Meiotic Segregation, Synapsis, and Recombination Checkpoint Functions Require Physical Interaction between the Chromosomal Proteins Red1p and Hop1p. Molecular and Cellular Biology 20:6646-6658

Yang $\mathrm{F}$ et al. (2008) Meiotic failure in male mice lacking an X-linked factor. Genes \& development 22:682-691

Yang F et al. (2015) TEX11 is mutated in infertile men with azoospermia and regulates genome-wide recombination rates in mouse. EMBO Mol Med 7:1198-1210 
Yatsenko AN et al. (2015) X-linked TEX11 mutations, meiotic arrest, and azoospermia in infertile men. N Engl J Med 372:2097-2107

Yokoo R, Zawadzki KA, Nabeshima K, Drake M, Arur S, Villeneuve AM (2012) COSA-1 reveals robust homeostasis and separable licensing and reinforcement steps governing meiotic crossovers. Cell 149:75-87

Yoshida K, Kondoh G, Matsuda Y, Habu T, Nishimune Y, Morita T (1998) The mouse RecA-like gene Dmc1 is required for homologous chromosome synapsis during meiosis. Mol Cell 1:707-718

Zakharyevich K, Ma Y, Tang S, Hwang PY, Boiteux S, Hunter N (2010) Temporally and biochemically distinct activities of Exo1 during meiosis: double-strand break resection and resolution of double Holliday junctions. Molecular Cell 40:1001-1015

Zakharyevich K, Tang S, Ma Y, Hunter N (2012) Delineation of joint molecule resolution pathways in meiosis identifies a crossover-specific resolvase. Cell 149:334-347

Zalevsky J, MacQueen AJ, Duffy JB, Kemphues KJ, Villeneuve AM (1999) Crossing over during Caenorhabditis elegans meiosis requires a conserved MutS-based pathway that is partially dispensable in budding yeast. Genetics 153:1271-1283

Zhang L, Espagne E, de Muyt A, Zickler D, Kleckner NE (2014a) Interference-mediated synaptonemal complex formation with embedded crossover designation. Proceedings of the National Academy of Sciences of the United States of America 111:E5059-E5068

Zhang L, Kim KP, Kleckner NE, Storlazzi A (2011) Meiotic double-strand breaks occur once per pair of (sister) chromatids and, via Mec1/ATR and Tel1/ATM, once per quartet of chromatids. Proc Natl Acad Sci U S A 108:20036-20041

Zhang L, Köhler S, Rillo-Bohn R, Dernburg AF (2018a) A compartmentalized signaling network mediates crossover control in meiosis. eLife 7

Zhang L, Tang D, Luo Q, Chen X, Wang H, Li Y, Cheng Z (2014b) Crossover formation during rice meiosis relies on interaction of OsMSH4 and OsMSH5. Genetics 198:1447-1456

Zhang L, Wang S, Yin S, Hong S, Kim KP, Kleckner N (2014c) Topoisomerase II mediates meiotic crossover interference. Nature 511:551-556

Zhang Q, Ji SY, Busayavalasa K, Yu C (2019) SPO16 binds SHOC1 to promote homologous recombination and crossing-over in meiotic prophase I. Sci Adv 5:eaau9780

Zhang Q, Shao J, Fan H-Y, Yu C (2018b) Evolutionarily-conserved MZIP2 is essential for crossover formation in mammalian meiosis. Communications Biology 1:147

Zhang W, Song X, Ni F, Cheng J, Wu BL, Jiang H (2017) Association analysis between HFM1 variations and idiopathic azoospermia or severe oligozoospermia in Chinese Men. Sci China Life Sci 60:315-318

Zickler D (2006) From early homologue recognition to synaptonemal complex formation. Chromosoma 115:158-174

Zickler D, Kleckner N (1999) Meiotic chromosomes: integrating structure and function. Annual Review of Genetics 33:603-754

Zickler D, Kleckner N (2015) Recombination, Pairing, and Synapsis of Homologs during Meiosis. Cold Spring Harbor Perspectives in Biology 7:a016626 
Table and figure Legends

Table 1: Homologs of ZMM proteins identified in model organisms and corresponding references.

\section{Figure 1: Model of meiotic recombination with corresponding changes in chromosome structure}

Left: Representation of the three main pathways of meiotic recombination. Parental double-stranded DNA molecules are depicted in blue and red. Dashed lines indicate newly synthesized DNA. Meiotic double-strand breaks (DSBs) formed by Spo11 can be repaired as two types of recombination products: crossovers (COs) and non-crossovers (NCOs), which correspond to DSB repair products with and without exchange of flanking sequences, respectively. COs produced by the ZMM pathway are formed via stabilized DLoop (the single-end invasion (SEI)) and double-Holliday-junction (dHJ) intermediates, and exhibit interference. Nevertheless, some CO-specific recombination intermediates may be redirected towards NCO products following ZMM loading (dashed arrow). By contrast to ZMM-dependent COs, the non-interfering COs are randomly distributed along the chromosomes. Non-interfering COs are produced simultaneously with NCOs by the resolution by structure-specific nucleases of DNA intermediates that have escaped from helicases or ZMM activities. The estimated percentage of interfering COs over the total number of COs in different organisms is shown: S.c.: Saccharomyces cerevisiae; M.m.: Mus musculus; A.t.: Arabidopsis thaliana; C.e.: Caenorhabditis elegans (Serrentino and Borde 2012). The disassembly of DNA intermediates by helicase(s) leads to NCO products. Right: Illustrations of the corresponding changes in chromosome structure are shown for a single pair of homologous chromosomes (red and blue lines).

\section{Figure 2: Relationships between ZMM proteins in S. cerevisiae}

(a) Table indicating the interdependency between ZMM proteins for localization on chromosomes. Green cells indicate the presence of ZMM proteins while red cells indicate abolished or altered binding of ZMM proteins to chromosomes. Not tested dependency is indicated by a grey cell. Different types of Zip1 staining (dots or lines) are specified. PC: polycomplex. References are also indicated: (1) (Chua and Roeder 1998); (2) (Tsubouchi 
et al. 2006); (3) (Shinohara et al. 2008); (4) (Nishant et al. 2010) (ㅁ) (Serrentino et al. 2013); (6) (De Muyt et al. 2018). Underlined and non-underlined references refer to chromatin immunoprecipitation (ChIP) and immunolocalization data, respectively.

(b) Physical interactions observed among ZMM proteins. Interactions between ZMM members, the MutL $\beta$ complex and the synaptonemal complex are also showed. Red and black arrows correspond to interactions identified by yeast two-hybrid and coimmunoprecipitation, respectively. References for yeast two-hybrid: (Agarwal and Roeder 2000; Cheng et al. 2006; De Muyt et al. 2018; Duroc et al. 2017; Hollingsworth and Ponte 1997; Humphryes et al. 2013; Pochart et al. 1997). References for coimmunoprecipitation: (Agarwal and Roeder 2000; Cheng et al. 2006; De Muyt et al. 2018; Duroc et al. 2017; Humphryes et al. 2013; Shinohara et al. 2008; Woltering et al. 2000).

\section{Figure 3: Proposed model for ZMM-dependent formation of interfering $\mathrm{CO}$ and polymerization of the synaptonemal complex.}

Left: progressive implementation of interfering $\mathrm{CO}$ by the ZMM proteins. Budding yeast proteins are shown. Details are in the text. For simplicity, phosphorylated Zip1 protein is not shown on recombination intermediate of steps a-c. Recombination steps b and c consider the binding of Msh4-5 complexes on duplex DNA but does not exclude the possibility that they entrap the entire $\mathrm{dHJ}$.

Right: ZMM-mediated recruitment of SC central components (orange rods).

Chromosome bridges are formed during the transit of ZMM proteins from the chromosome axis to the inter-axis space. SC nucleation then occurs which brings axes closer together, allowing SC polymerization initiation. See also the text for more details. The electron microscopy image in (i) represents axes association via interhomolog bridges (Albini and Jones 1987). The SC polymerizes and chromosomes are synapsed at a precise distance of $100 \mathrm{~nm}$. The electron microscopy image in (ii) represents a pair of synapsed chromosomes with a recombination site also known as a recombination nodule (RN) (From (del Cacho et al. 2005)). See also (Zickler and Kleckner 2015) for more details about inter-axis coalignment and synapsis. 


\begin{tabular}{|c|c|c|c|c|c|c|c|c|}
\hline S.cerevisiae & Molecular function & S. macrospora & M.musculus & A. thaliana & C.elegans & D.melanoglisteren & ie to access/dReferendes Table;Table1 & frevised\#2.pdf $\stackrel{\underline{\underline{ }}}{\mathrm{f}}$ \\
\hline Zip1 & $\begin{array}{l}\text { Coiled-coil protein } \\
\text { Polymerizes to form the central element of the SC } \\
\text { Regulated by phosphorylation of the C-terminal part } \\
\text { Recruited prior to other ZMMs }\end{array}$ & Sme4 & SYCP1 & $\begin{array}{l}\text { ZYP1a and } \\
\text { ZYP1b }\end{array}$ & $\begin{array}{l}\text { SYP-1 and } \\
\text { SYP-2 }\end{array}$ & c3G & $\begin{array}{l}\text { Meuwissen et al. } 1992 \\
\text { Sym et al. } 1993 \\
\text { Page and Hawley } 2001 \\
\text { MacQueen et al. } 2002 \\
\text { Colaiácovo et al. } 2003 \\
\text { Higgins et al. } 2005 \\
\text { Espagne et al. } 2011\end{array}$ & \\
\hline Mer3 & $\begin{array}{l}\text { DNA Helicase } \\
\text { Recruits MutL } \beta \text { (Mlh1-Mlh2) to limit D-loop extension } \\
\text { during DNA synthesis }\end{array}$ & Mer3 & HFM1 & $\begin{array}{c}\text { AtMER3/ } \\
\text { Rock-N-Rollers }\end{array}$ & - & 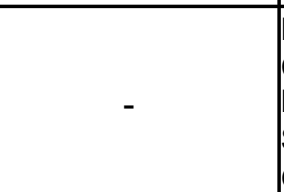 & $\begin{array}{l}\text { Nakagawa et al. } 1999 \\
\text { Chen et al. } 2005 \\
\text { Mercier et al. } 2005 \\
\text { Storlazzi et al. } 2010 \\
\text { Guiraldelli et al. } 2013\end{array}$ & \\
\hline Zip2 & $\begin{array}{l}\text { XPF protein forming an XPF-ERCC1-like complex with } \\
\text { Spo16 which binds to branched DNA structures in vitro } \\
\text { Part of the Zip2-Zip4-Spo16 (ZZS) complex }\end{array}$ & Zip2 & SHOC1/MZIP2 & SHOC1 & - & 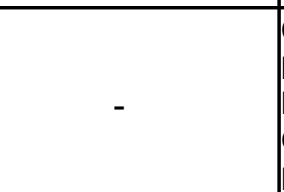 & $\begin{array}{l}\text { Chua and Roeder } 1998 \\
\text { Macaisne et al. } 2008 \\
\text { De Muyt et al. } 2018 \\
\text { Guiraldelli et al. } 2018 \\
\text { Dubois et al } 2019\end{array}$ & \\
\hline Spo16 & $\begin{array}{l}\text { ERCC1-like protein forming an XPF-ERCC1-like } \\
\text { complex with Zip2 which binds to branched DNA } \\
\text { structures in vitro } \\
\text { Part of the ZZS complex }\end{array}$ & - & SPO16 & PTD & - & 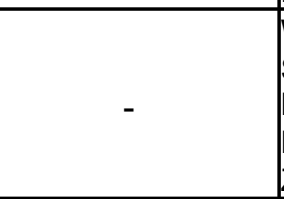 & $\begin{array}{l}\text { Wijeratne et al. } 2006 \\
\text { Shinohara et al. } 2008 \\
\text { Macaisne et al. } 2011 \\
\text { De Muyt et al. } 2018 \\
\text { Zhang et al } 2019\end{array}$ & \\
\hline Zip4 & $\begin{array}{l}\text { TPR motif protein } \\
\text { Part of the ZZS complex } \\
\text { Scaffold protein that has multiple protein-protein } \\
\text { interactions with ZMM and axis proteins }\end{array}$ & Zip4 & TEX11 & Zip4 & - & 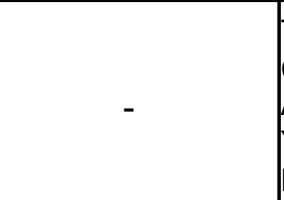 & $\begin{array}{l}\text { Tsubouchi et al. } 2006 \\
\text { Chelysheva et al. } 2007 \\
\text { Adelman et al. } 2008 \\
\text { Yang et al. } 2008 \\
\text { De Muyt et al. } 2014\end{array}$ & \\
\hline Zip3 & $\begin{array}{l}\text { RING finger protein } \\
\text { Probably involved in SUMO and/or ubiquitylation } \\
\text { (precise targets are unknown) }\end{array}$ & Hei10 & $\begin{array}{l}\text { HEI10 and } \\
\text { RNF212 }\end{array}$ & HEI10 & ZHP-3 & Vilya & $\begin{array}{l}\text { Agarwal and Roeder } 2000 \\
\text { Jantsch et al. } 2004 \\
\text { Ward et al. } 2007 \\
\text { Chelysheva et al. } 2012 \\
\text { Reynolds et al. } 2013 \\
\text { Qiao et al. } 2014 \\
\text { Lake et al. } 2015 \\
\text { De Muyt et al. } 2014\end{array}$ & \\
\hline Msh4 & $\begin{array}{l}\text { Forms a complex with Msh5 (MutSy complex) in order } \\
\text { to bind recombination intermediates such as D-loops } \\
\text { and HJs } \\
\text { Stabilized at future CO sites by phosphorylation of its } \\
\text { N-terminal region }\end{array}$ & Msh4 & $\mathrm{MSH} 4$ & AtMSH4 & HIM-14/MSH-4 & 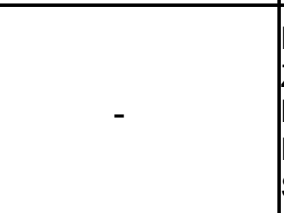 & $\begin{array}{l}\text { Ross-MacDonald and Roeder } 1994 \\
\text { Zalevsky et al. } 1999 \\
\text { Kneitz et al. } 2000 \\
\text { Higgins et al. } 2004 \\
\text { Storlazzi et al. } 2010\end{array}$ & \\
\hline Msh5 & $\begin{array}{l}\text { Forms a complex with Msh5 (MutSy complex) that } \\
\text { binds in vitro to recombination intermediates such as } \\
\text { D-loops and HJs }\end{array}$ & - & MSH5 & AtMSH5 & $\mathrm{MSH}-5$ & 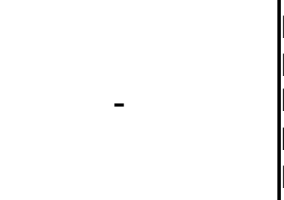 & $\begin{array}{l}\text { Hollingsworth et al. } 1995 \\
\text { Edelmann et al. } 1999 \\
\text { De Vries et al. } 1999 \\
\text { Kelly et al. } 2000 \\
\text { Higgins et al. } 2008\end{array}$ & \\
\hline
\end{tabular}




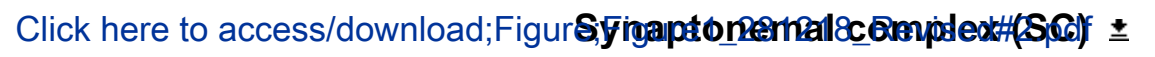

Paternal chromatid

Maternal chromatid

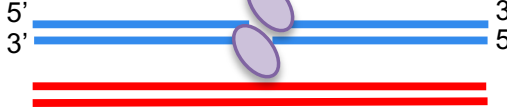
DSB formation

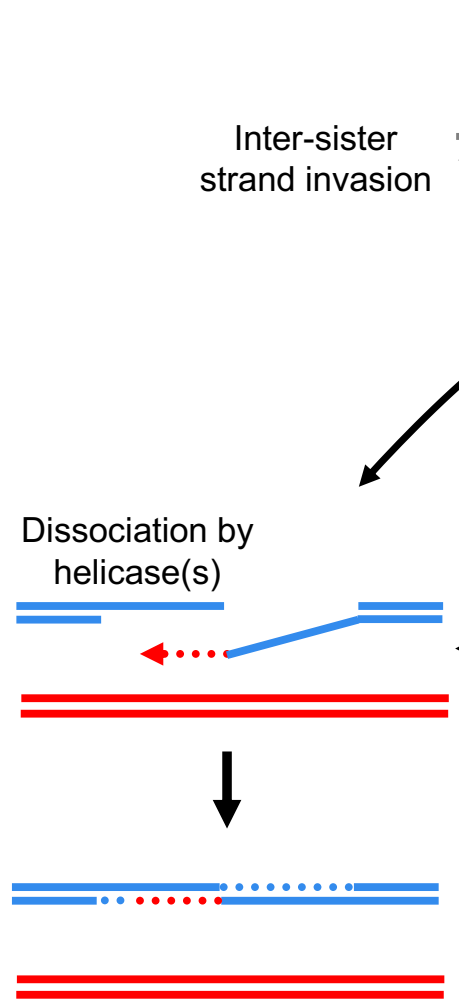

NCOs
5 ' to 3 '

Resection
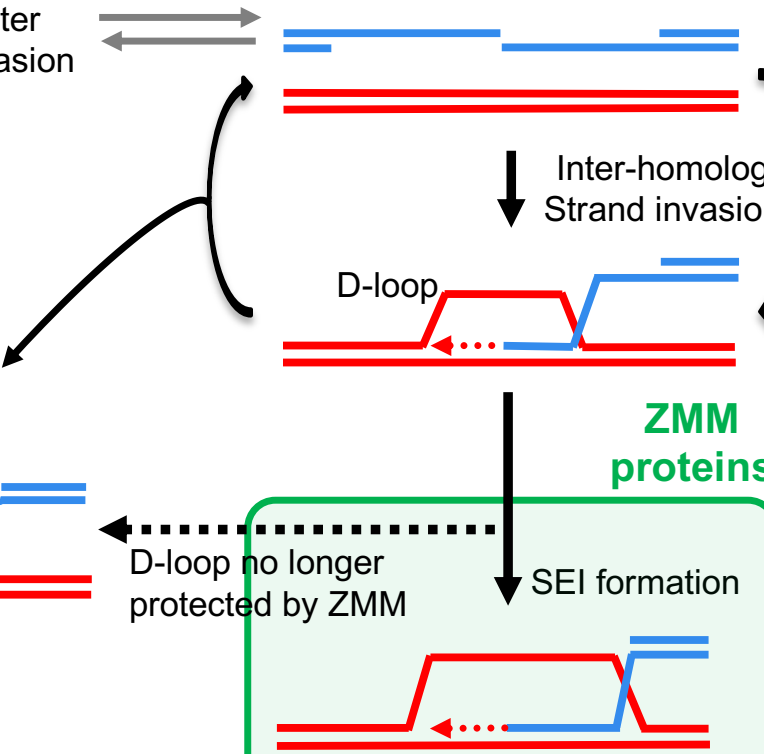

$\downarrow \mathrm{dHJ}$ formation

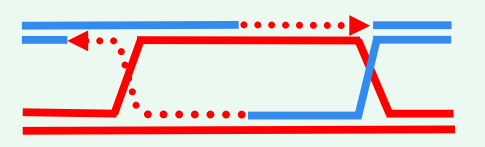

$\mathrm{dHJ}$ resolution (Mlh1-Mlh3)

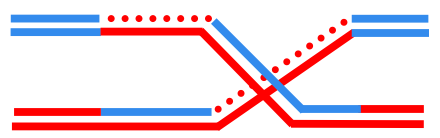

Interfering COs

S.c.: 75-85; M.m.: 90-95;

A.t.: 85; C.e.:100

$\%$ total COs
Polymerization of the SC axial elements

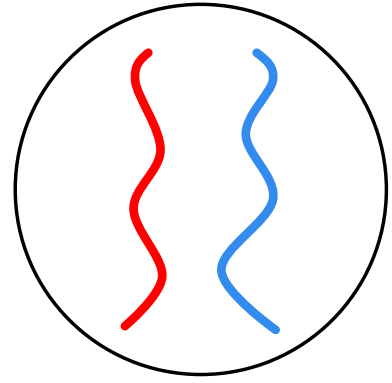

Initiation of synapsis

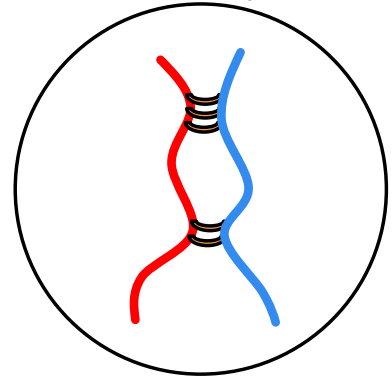

Polymerization of the SC central region

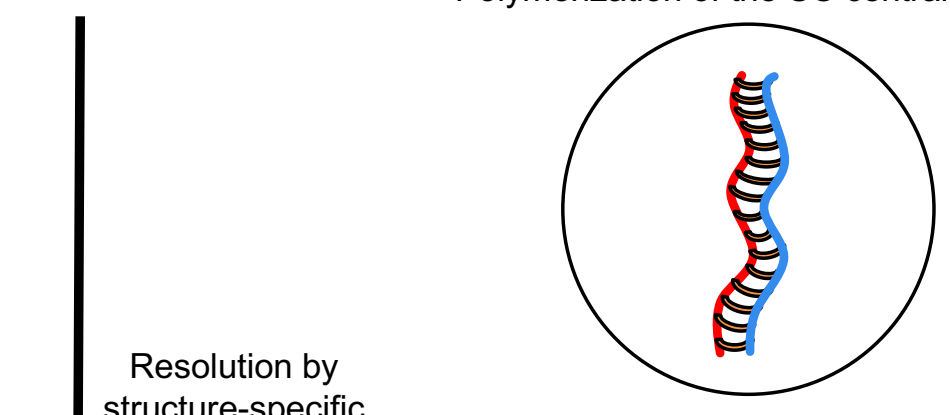

structure-specific nucleases (SSNs)

NCOs

and

non-interfering COs
Disassembly of the SC

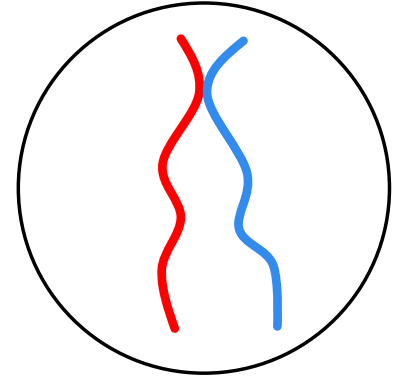


Fagure2 Interdependency between ZMM proteiglick

\begin{tabular}{|c|c|c|c|c|c|c|c|c|}
\hline & Zip1 & Zip2 & Zip3 & Zip4 & Spo16 & Msh4 & Msh5 & Mer3 \\
\hline $\operatorname{zip1} \Delta$ & & (1) & (3) & (3) & (3) & (3) & (3) & \\
\hline zip2 $\Delta$ & $\mathrm{PC}(1)$ & & (2) & $\mathrm{PC}(2) /(\underline{6})$ & (ㅁ) & & & \\
\hline zip3 $\Delta$ & $\mathrm{PC}(3)$ & $\mathrm{PC}(2)$ & & $\mathrm{PC}(2)(3)$ & PC (3) & $\mathrm{PC}(3)$ & $\mathrm{PC}(3)$ & \\
\hline zip4 4 & Dots/PC (3) & $\mathrm{PC}(2) /(\underline{6})$ & (3) & & (3) (ㅁ) & (3) & (3) & \\
\hline spo16 $\Delta$ & Dots/PC (3) & ( 6 ) & (3) & (3) $(\underline{6})$ & & (3) & (3) & \\
\hline $\operatorname{msh} 4 \Delta$ & Dots/lines (3) & $(3)(\underline{6})$ & (3) & (3) (ㅁ) & (3) & & (3) (4) & \\
\hline msh5 $\Delta$ & PC (4) & & & & & & & \\
\hline \multicolumn{9}{|l|}{ mer3 $\Delta$} \\
\hline & \multicolumn{2}{|c|}{ Normal binding } & \multicolumn{2}{|l|}{ No binding } & \multicolumn{4}{|c|}{ (Underlined reference): ChIP data } \\
\hline & Impaired bind & & Vo data & & (Reference & munocy & data & \\
\hline
\end{tabular}

b

Physical interaction among ZMM proteins

MutL $\beta$ complex

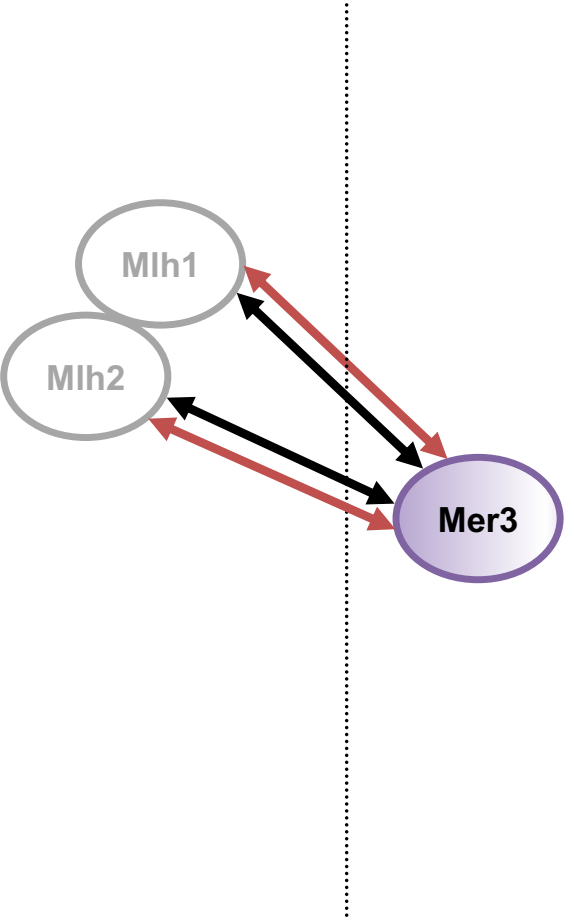

ZMM proteins

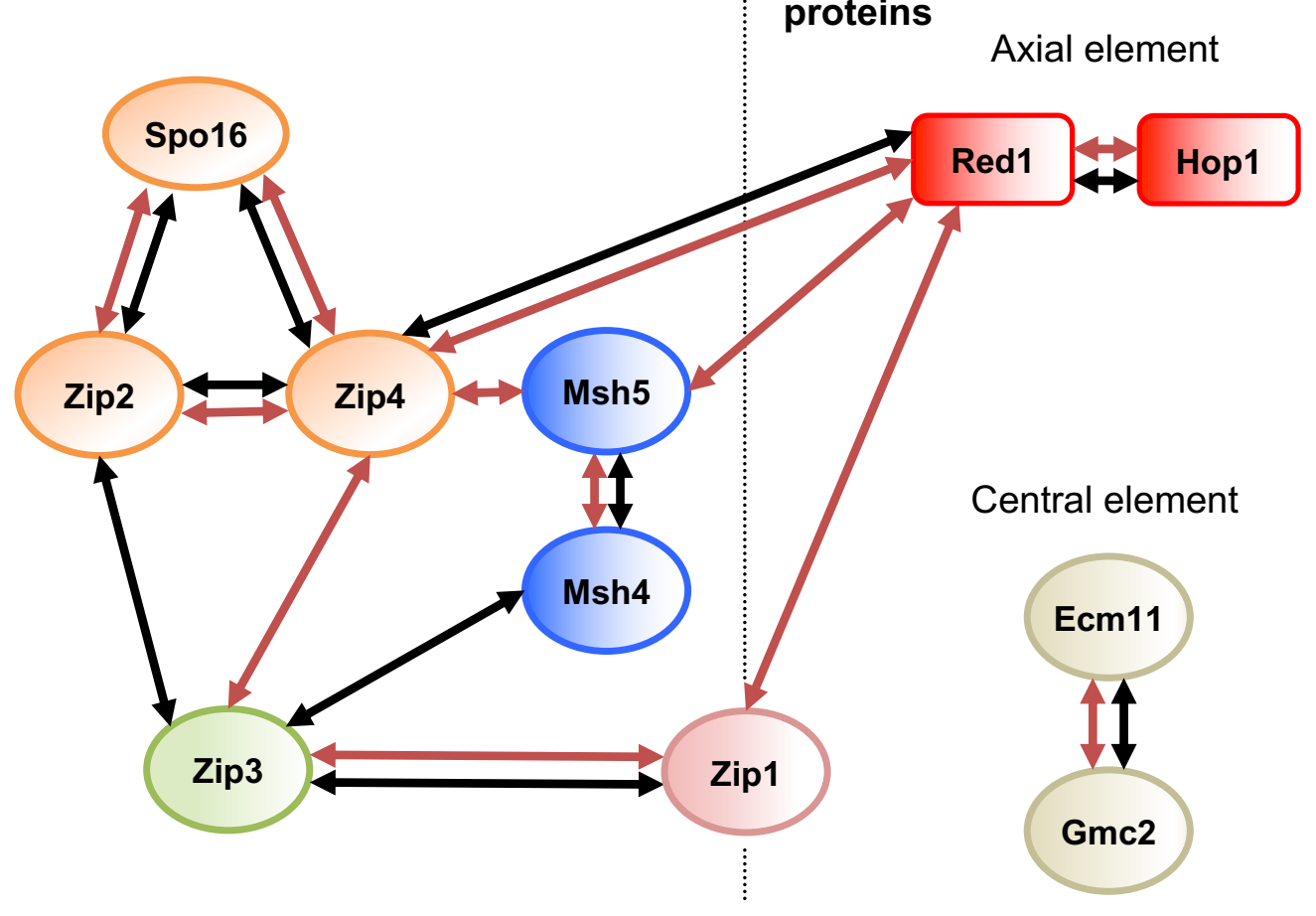

$\longleftrightarrow$ Interaction observed by co-immunoprecipitation

$\longleftrightarrow$ Interaction observed by yeast two-hybrid 

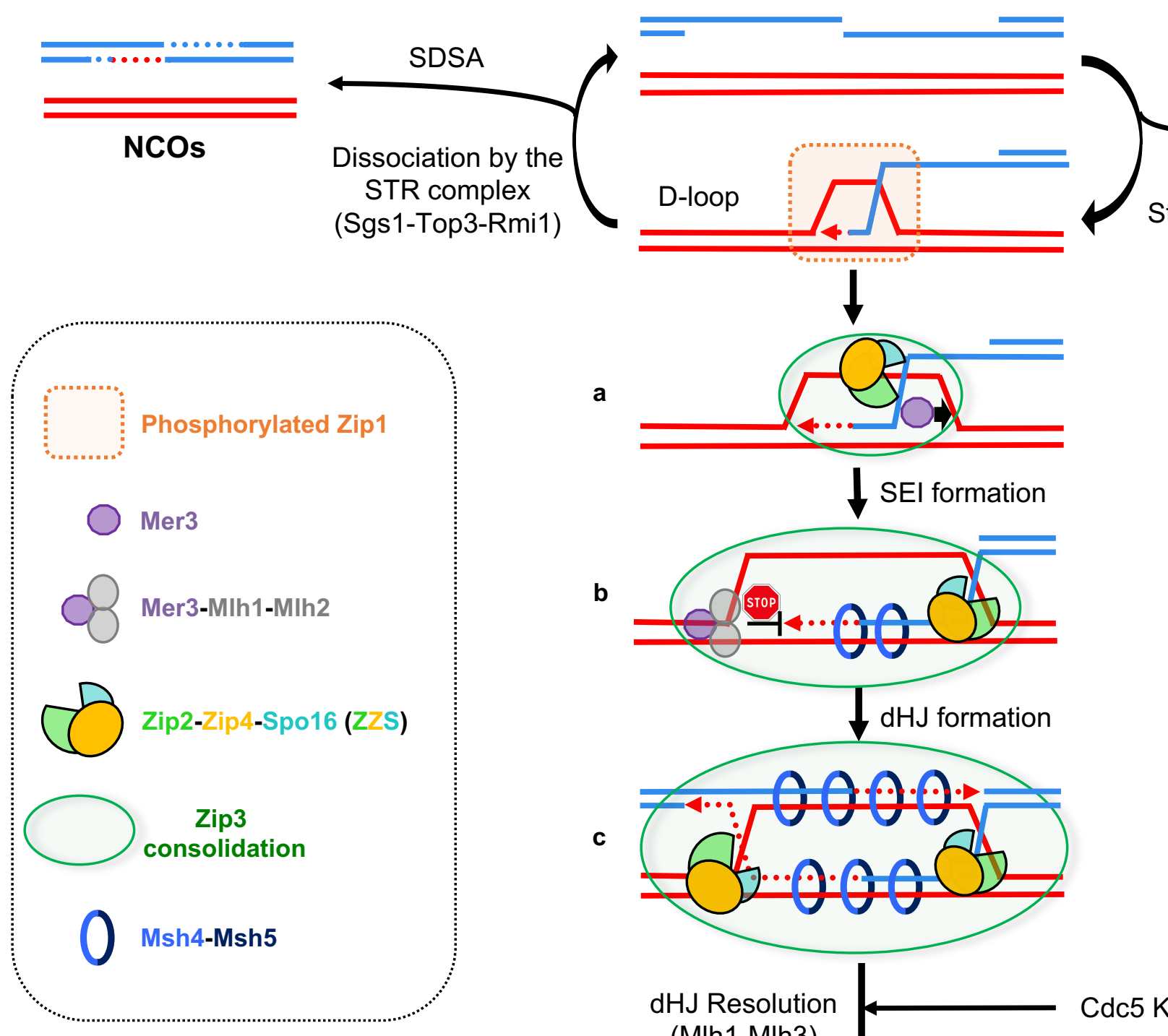
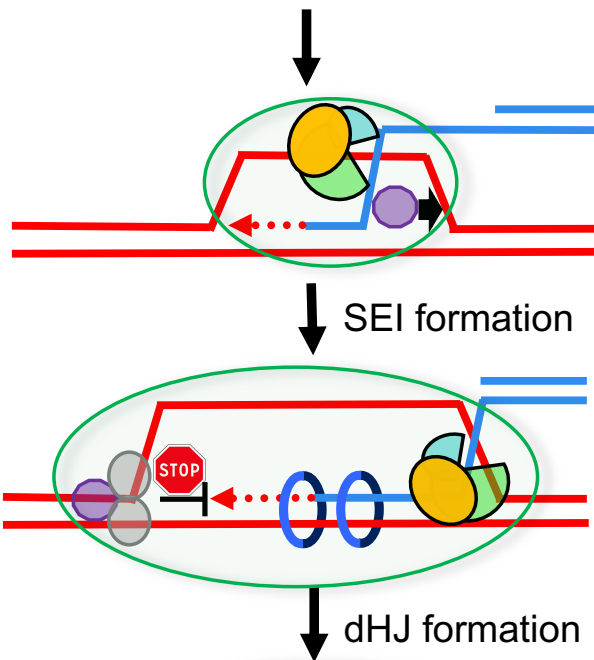

c
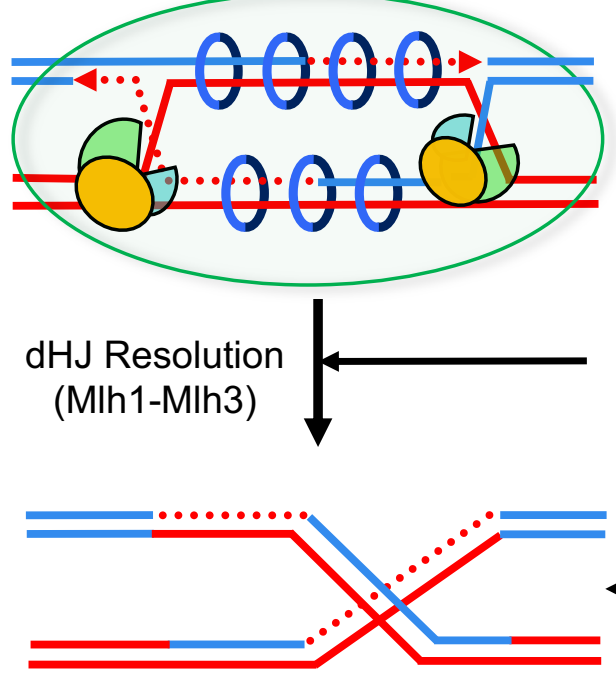

Interfering COs

Strand invasion

\section{Synaptonemal complex formation}

Close axis association and formation of SICs

(i)

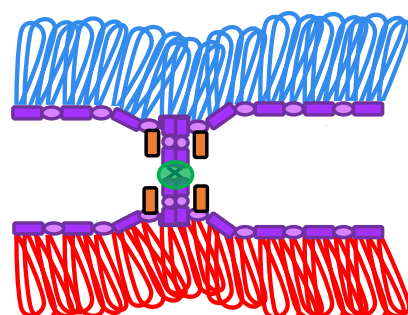

$\downarrow$ SC polymerization

(ii)

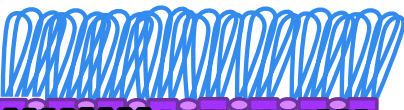

.

W.

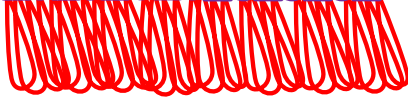
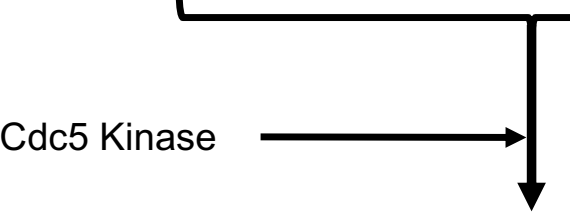

SC breakdown

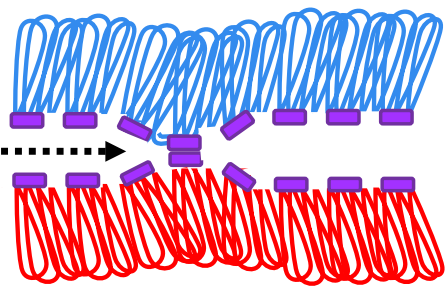

ZMM proteins

(including Zip1)

SC axial elements

(Red1, Hop1 and cohesins)

SC transverse filament (Zip1)

- SC central elemen (Ecm11, Gmc2) 